\title{
Spectral optical properties of the polluted atmosphere of Mexico City (spring - summer 1992)
}

\author{
O. B. Vasilyev,' A. Leyva Contreras, A. Muhlia Velazquez, and R. Peralta y Fabi \\ Instituto de Geofisica y Instituto de Ingenieria, National Autonomous University of Mexico \\ (UNAM), Cd. Universitaria,. Mexico City, Mexico
}

\author{
L. S. Ivlev, A. P. Kovalenko, A. V. Vasilyev, and V. M. Jukov \\ Institute of Physics, Saint Petersburg State University, Saint Petersburg, Russia
}

Ronald M. Welch

Institute of Atmospheric Sciences, South Dakota School of Mines and Technology, Rapid City

\begin{abstract}
A joint Mexican, Russian, and American research effort has been initiated to develop new methods to remotely sense atmospheric parameters using ground-based, aircraft, and satellite observations. As a first step in this program, ground-based spectrophotometric measurements of the direct solar radiation have been obtained for the extremely polluted Mexico City atmosphere for the period of April-June 1992. These observations were made at more than 1300 channels in the spectral range of $0.35-0.95 \mu \mathrm{m}$. In the ultraviolet (UV) portions of the spectrum (e.g., $0.35 \mu \mathrm{m}$ ), aerosol optical thicknesses were found to range between 0.6 and 1.2 ; in the visible portion of the spectrum (e.g., $0.5 \mu \mathrm{m}$ ) they ranged from 0.5 to 0.8 ; and in the near-infrared (NIR) spectra (e.g., $0.85 \mu \mathrm{m}$ ), values of $0.3-0.5$ were found. Applying a spectral optical depth (SOD) model of $\tau(\lambda)=C+A \lambda^{-\infty}$, values of $1.55<\propto<1.85$ were obtained for polluted, cloudless days, with values of $1.25<\propto<1.60$ on days with haze. The aerosol particles in the polluted Mexico City atmosphere were found to be strongly absorbing, with a single-scattering albedo of $0.7-0.9$ in the UV, $0.6-0.8$ in the visible portion of the spectrum, and $0.4-0.7$ in the NIR. These values are possibly consistent with a high soot concentration, contributed both by vehicular traffic and heavy industry. Analysis of the measured aerosol SOD using the optical parameters of an urban aerosol model permits the concentration of aerosol particles to be estimated in the vertical column; a maximum value of $3 \times 10^{9} \mathrm{~cm}^{-2}$ was found. This concentration of aerosol particles exceeds that found in most other regions of the globe by at least an order of magnitude. Near the ground the aerosol size distributions measured using an optical particle counter were found to be strongly multimodal.
\end{abstract}

\section{Introduction}

Aerosols, both anthropogenic and natural, are considered to be uncertain but potentially important climate feedback mechanisms [Rasool, 1973; Schneider, 1976; Hansen and Lacis, 1990; Mitchell, 1991]. Aerosols reflect sunlight back toward space, thereby cooling the Earth's surface. They also cool the planet indirectly by providing cloud condensation nuclei (CCN) upon which water vapor condenses into cloud droplets. Large concentrations of small droplets make the clouds more reflective to sunlight [Coakley et al., 1983]. Furthennore, observations demonstrate that aerosols increase cloud reflectivity by inhibiting rainfall and prolonging cloud

\footnotetext{
'Deceased June 10, 1995.

Copyright 1995 by the American Geophysical Union.

Paper number $95 \mathrm{JD} 02370$.

0148-0227/95/95JD-02370\$05.00
}

lifetimes [Albrecht, 1989]. On the other hand, some aerosols may strongly absorb solar radiation, thereby heating the terrestrial atmosphere [Kondratyev et al., 1974a, b, 1977, 1981; Welch et al., 1981; Vasilyev et al., 1993]. Such aerosol particles located on the surface of water droplets also may increase the absorbtivity of cloud layers [Twohy et al., 1989]. The net result is that changing amounts of anthropogenic aerosols may contribute to changed radiative forcing and thus to climate change.

Current climate forcing by anthropogenic sulfate is estimated to be of the order of -1 to $-2 \mathrm{~W} / \mathrm{m}^{2}$, which is comparable in magnitude but opposite in sign to greenhouse gas forcing [Charlson et al., 1992]. Aerosol forcing may make a significant contribution to offsetting global greenhouse warming; however, there are large uncertainties in our understanding of the magnitude of these effects.

The radiative balance in the atmosphere is strongly influenced by the scattering and absorbing characteristics of aerosols. Nonabsorbing aerosols only increase the albedo of the 
surface-atmosphere system, thereby cooling the surface [Kondratyev et al., 1973]. However, for absorbing aerosols and especially highly absorbing aerosols such as soot the effects become more complicated. Indeed, the radiative balance of the surface-atmosphere system depends upon both the sign and the magnitude of the difference between the surface albedo and the reflectivity of the aerosol layer [Kondratyev et al., 1973, 1977; Kondratyev and Vasilyev, 1975]. For cases of a dark underlying surface (i.e., low albedo), the presence of aerosols produces a net increase in the atmosphere-surface system albedo. On the other hand, for bright surfaces, some aerosols may produce a net decrease in system albedo.

A long series of airborne observations of radiative flux divergences have been carried out in Russia for a large variety of atmospheric conditions [Kondratyev et al., 1974a, b, 1977, 1981; Vasilyev, 1993]. For very dusty or highly polluted atmospheres the solar radiation absorbed by aerosols may reach values equivalent to gaseous absorption. Similarly, aerosol scattering of solar radiation may reach values equivalent to scattering by the molecular atmosphere. However, the measurements show large geographical and seasonal variations of aerosol effects and hence of aerosol radiative forcings on climate.

Atmospheric aerosol particles generated from dust storms [Carlson, 1979] and smoke from forest fires [Chung and Le, 1984] are important regional climatic variables. Large particle concentrations produced from these types of events often are found with optical thicknesses greater than one. These aerosol particles also are transported across great distances from the source [Fraser et al., 1984], and they perturb the radiative balance significantly, both on local and on regional scales. Heavy dust loading can change the top-of-theatmosphere clear sky shortwave and longwave radiative existence by $40-90 \mathrm{~W} / \mathrm{m}^{2}$ and $5-20 \mathrm{~W} / \mathrm{m}^{2}$, respectively [Ackerman and Chung, 1992].

Sulfate is one of the important sources of tropospheric aerosols. Sulfur dioxide emissions are produced by both anthropogenic [Schwartz, 1988] and by natural [Charlson et al., 1987] sources. Schwartz [1988] argues that anthropogenic $\mathrm{SO}_{2}$ emissions cannot be neglected in analyzing the global cloud albedo-climate issue [Charlson et al., 1992].

Large urban areas often are sources of extremely heavy pollution, affecting both the radiation balance and the climate for extended regions around them and the health of the population within them [Ensor et al., 1974]. For example, the aerosol concentrations in the Grand Canyon are contributed to by both the Los Angeles basin, hundreds of miles to the west, and by Phoenix to the south. Pollution from North America is routinely tracked all the way to Europe, and both North America and Europe strongly contribute to Arctic haze. Urban pollution sources are continuous, thereby contributing to the overall regional background aerosol concentrations.

The Mexico City atmosphere is widely held to be the most heavily polluted region on the planet. The source of the aerosols is a combination of heavy vehicular traffic and heavy industry, neither of which has any significant emission requirements. Indeed, the heavy pollution found in Mexican cities is an international issue and a consideration in the North American Free Trade Agreement (NAFTA). Therefore the first site for a joint Mexican, Russian, and American research effort, initiated to develop new methods to remotely sense atmospheric parameters using ground-based, aircraft, and satellite observations, is Mexico City. As a first step in this research program, ground-based spectrophotometric measurements of the direct solar radiation have been obtained in Mexico City for the period of April-June 1992.

Note that most retrieved measurements of aerosol concentrations and size distributions reported in the literature are based on single or, at most, a few wavelengths. In contrast, the present observations have been made at more than 1300 channels in the spectral range of $0.35-0.95 \mu \mathrm{m}$. This wide range of wavelengths allows a significant improvement in characterizing the polluted atmosphere. Section 2 discusses the instrumentation, and section 3 describes the sites and conditions of the observations. Section 4 outlines the methodology; section 5 reports the results; and conclusions are presented in section 6 .

\section{Instrumentation}

Measurements of the spectral optical depth (SOD) in Mexico City during April-June 1992 were made using the spectral information measuring system (SIMS), consisting of (1) an optical unit, including a projection optical system and an obturator of the light beam; (2) a grating monochromator, (3) an electronic amplifying and directing unit; and (4) a registering and preliminary processing unit (i.e., PC computer). The principal element of SIMS is the grating monochromator (the Russian K-2 or K-3), which was designed using the vertically symmetric scheme of Ebert-Fastie. The main parameters of the K-2 and K-3 instruments are listed in Table 1. Schematic and interior views of the $\mathrm{K}-3$ monochromator are shown in Figure 1. The K-2 and K-3 spectrophotometers were designed and manufactured in the Laboratory of Experimental Atmospheric Optics at the Institute of Physics at St. Petersburg State University (IPh SPbSU) [Vasilyev et al., 1987].

The two concave spherical mirrors have focal lengths of 193 inches $(482.5 \mathrm{~mm})$ and the plane grating has 600 lines $/ \mathrm{mm}$. The first order of diffraction is used. With a spectral resolution of 0.005 (i.e., 1/200) the output slit linear resolution is 33 $\mathrm{A} / \mathrm{mm}$. By rotating the grating, output from the various wavelengths is measured. The measuring time is $7 \mathrm{~s}$, and the time of returning the grating to its starting position is $3 \mathrm{~s}$. Radiation dispersed by the grating falls on three output slits and is received by three photomultipliers (the UV, visible (VIS), and NIR portions of the spectrum). Each output slit has a glass correction filter to "cut off" the higher orders of diffraction.

Measurements of radiative fluxes are made using opaque glass mounted on the entrance objective. Their "cosine law" was found to deviate by less than $0.5 \%$ for angles less than $70^{\circ}$. Measurements of direct solar radiation then were made using this opaque glass and a long tube with an entrance diaphragm to limit the field of view of the instrument.

During the measurement process, instrument stability was controlled using a lamp mounted inside the monochromator. Before the observations were taken, this calibration lamp was compared to a standard source Russian SI-8 lamp. In turn, this standard lamp was calibrated using a "blackbody" source of light at the Shternberg Astronomical Observatory at Moscow State University.

The "warm-up" time of the instrument is about $1 / 2$ hour. During the measurements, variations of the signal were found to be $1-2 \%$. The lamp inside the monochromator was not 
Table 1 Main Parameters of K-2 and K-3 Instruments

\begin{tabular}{ll}
\hline \multicolumn{1}{c}{ Instrument Parameter } & \multicolumn{1}{c}{ Value } \\
\hline Dispersing element & Diffraction Grating, $600 \mathrm{~mm}^{-1}$ \\
Order of diffraction & 1 \\
Spectral range & $0.35-0.95 \mu \mathrm{m}$ \\
Sensors & \\
three photomultipliers & $\mathrm{UV}, 0.35-0.42 \mu \mathrm{m}$ \\
$\quad$ for three channels & $\mathrm{VIS}, 0.42-0.70 \mu \mathrm{m}$ \\
& $\mathrm{IR}, 0.70-0.95 \mu \mathrm{m}$ \\
Spectral resolution & $1: 200$ \\
Discrimination Sensitivity & $0.1 \mathrm{~mW} / \mathrm{cm}^{2} \mu \mathrm{m}$ \\
Field of view & $1^{\circ} \times 10^{\prime}$ or $180^{\circ}$ \\
Measuring time & $7 \mathrm{~s}$ \\
Operating voltage & $27 \mathrm{~V}$ \\
Consumed power & $200 \mathrm{~W}$ \\
& \\
\hline
\end{tabular}

thermostated; since luminosity is proportional to $\mathrm{T}^{4}$, this 1$2 \%$ signal variability may be traced to a $1 / 4-1 / 2 \%$ variability of the temperature ( $\mathrm{T}$ ) of the lamp's filament. In absolute values this variation represents changes of the lamp's filament temperature of $6^{\circ}-12^{\circ} \mathrm{C}$, referenced to the original temperature of about $2400^{\circ} \mathrm{C}$. As a result, all measurements taken using SIMS had an accuracy of about $1-2 \%$. The calculated values of SOD have a similar accuracy.

\section{Measurement Sites and Conditions of Observations}

The north side of Mexico City is a region of heavy industry and the main source of industrial pollution. The main observational site for the measurements is the Observatory of Solar Radiation (ORS) at the Institute of Geophysics (IGf) of the Mexican Autonomous National University (UNAM), located in the southern part of Mexico City. This so-called "ecological zone" is a region in which air pollution is lower than in the center of the city. Observations were conducted from the roof of the Institute of Geophysics, UNAM, and in the central part of Mexico City at Tezozomoc Park, in one of the most polluted regions of the city.

Another series of measurements was taken at Tlamacas Station ( $4 \mathrm{~km}$ above sea level) on the slope at the Popocatepetl volcano. These observations were designed both for retrieving the background optical thickness measurements and for obtaining an absolute calibration of the K-3 spectrophotometer, which is necessary if the observations are conducted using the so-called "short method" (see section 4). However, the choice of the Tlamacas Station site proved to be unfortunate because measurements of the Sun had to be made in the direction of the city of Pueblo which is the second largest industrial center of Mexico. The air above this region also was found to be highly polluted and unusable for background retrievals and calibration purposes.

A series of observations also were taken in the presence of high cirrus cloudiness; therefore some estimates of cirrus SOD are included in the results.
The meteorological conditions prevailing during the period April-June 1992 generally permitted only a morning series of measurements, with the one exception being the afternoon of June 14. During a 2-month observational period a series of 24 observations were made, or approximately one series of observations each 3 days. On the other hand, there were periods of cloudiness lasting for up to 10 days when no measurements were made.

\section{Methodology}

The "long method" for the determination of spectral optical depth was used in this investigation [e.g., Liou, 1980]; that is, the direct solar radiation was measured at a series of different solar zenith angles, corresponding to different "air masses" (i.e., optical path lengths). Using Beer's law, the observed fluxes of direct solar radiation are expressed as

$$
S(\lambda)=S_{0}(\lambda) e^{-\tau(\lambda) m(z),},
$$

where $\lambda$ is wavelength; $S_{0}(\lambda)$ is the extra-atmospheric solar spectral flux (i.e., the so-called "spectral solar constant"), $\tau(\lambda)$ is the spectral optical depth, $z$ is the solar zenith angle, and $\mathrm{m}(\mathrm{z})$ is the air mass. Taking the logarithm of this equation,

$$
\ln S(\lambda)=\ln S_{0}(\lambda)-\tau(\lambda) m(z)
$$

a linear regression is obtained which may be solved using the least squares method.

The advantage of the "long method" is that the spectral optical depths (SODs) are obtained without requiring any calibration of the instrument, because they are relative, not absolute measurements. The linearity of the instrument was carefully examined in laboratory studies, and the stability of the instrument was controlled during the observations using a lamp mounted inside the monochromator (see section 2). The calibration of the instrument is critical for observations using the "short method," in which values of SOD are 
a

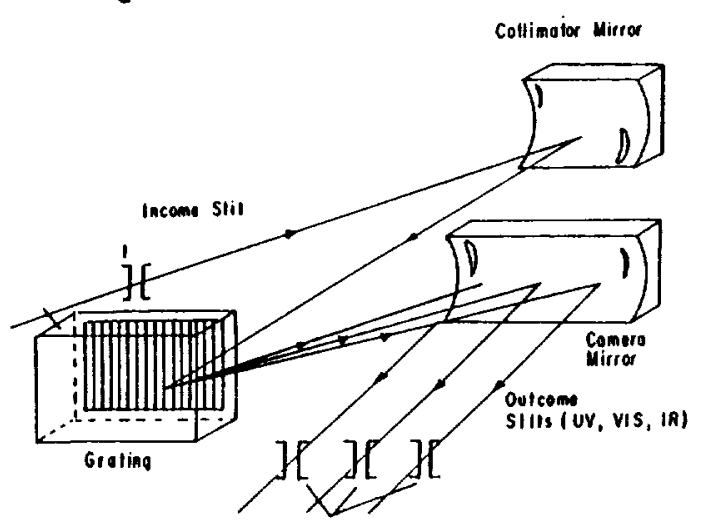

b

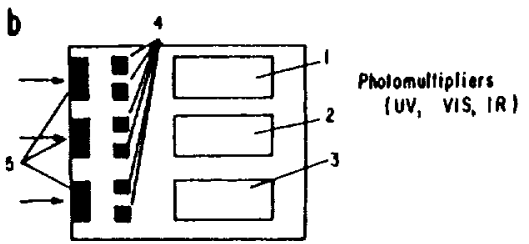

C
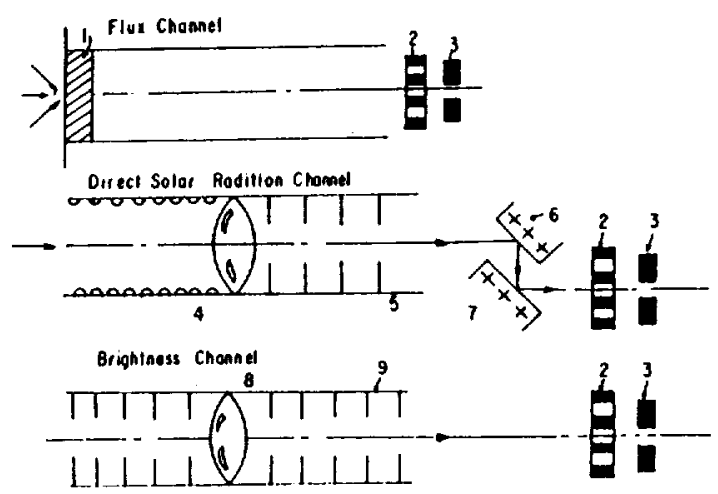

Colibralion Chonael

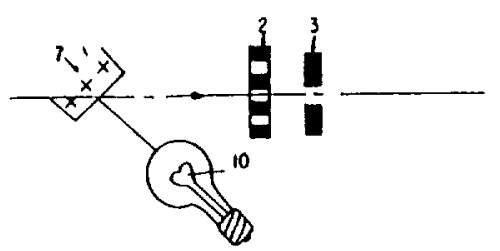

d

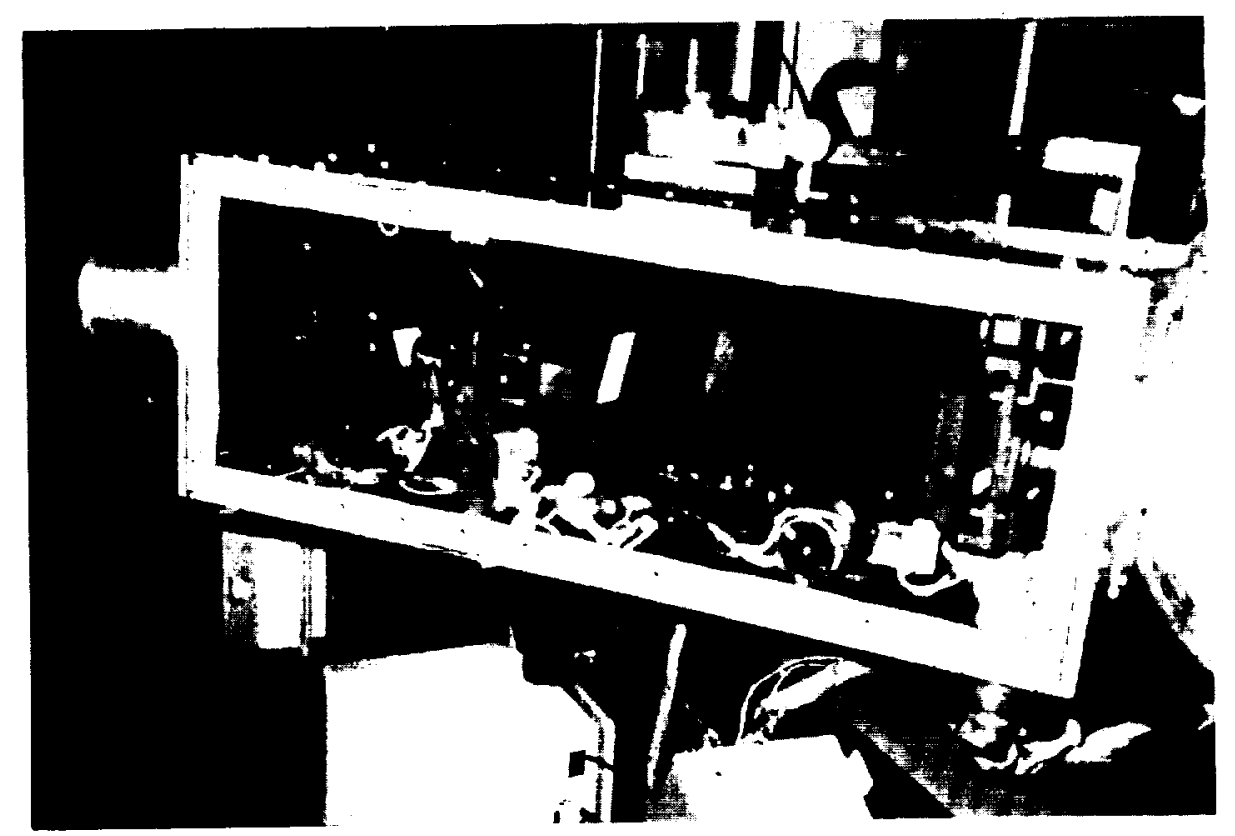

Figure 1. (a-c) Schematic and (d) interior view of the K-3 monochromator. (b) Numbers 1-3, photomultipliers; 4 , quartz windows; 5 , correction filters. (c) Number 1, opaque glass; 2 , obturator; 3 , income slit; 4 , solar blend; 5 and 9 , inner diaphragms; 6 and 7 , opaque screens, 8, objective; 20 , standard lamp.

$$
\tau(\lambda)=\frac{1}{m(z)} \ln \left[\frac{S_{0}(\lambda)}{S(\lambda)}\right]
$$

Figure 2 shows an example of the Langley plots in the ultraviolet (UV), visible (VIS), and near-infrared (NIR) portion of the spectra measured in Mexico City on April 12, 1993.

Most of the observations were made in the morning from 0700 to 0900 Local Standard Time (LST), during which time the atmosphere generally is expected to be stable. Nevertheless, the optical state of the atmosphere does begin to change during this period of time as the industrial plants begin operation and as the traffic density increases. Such variations may lead to errors in the retrieved results using the "long method." The optical path length varied from about 5 to about 2 , during which time the solar elevation ranged from $5^{\circ}$ to $30^{\circ}$. Because of the low latitude of Mexico City the Sun rises at a large angle with respect to the horizon; hence the change 

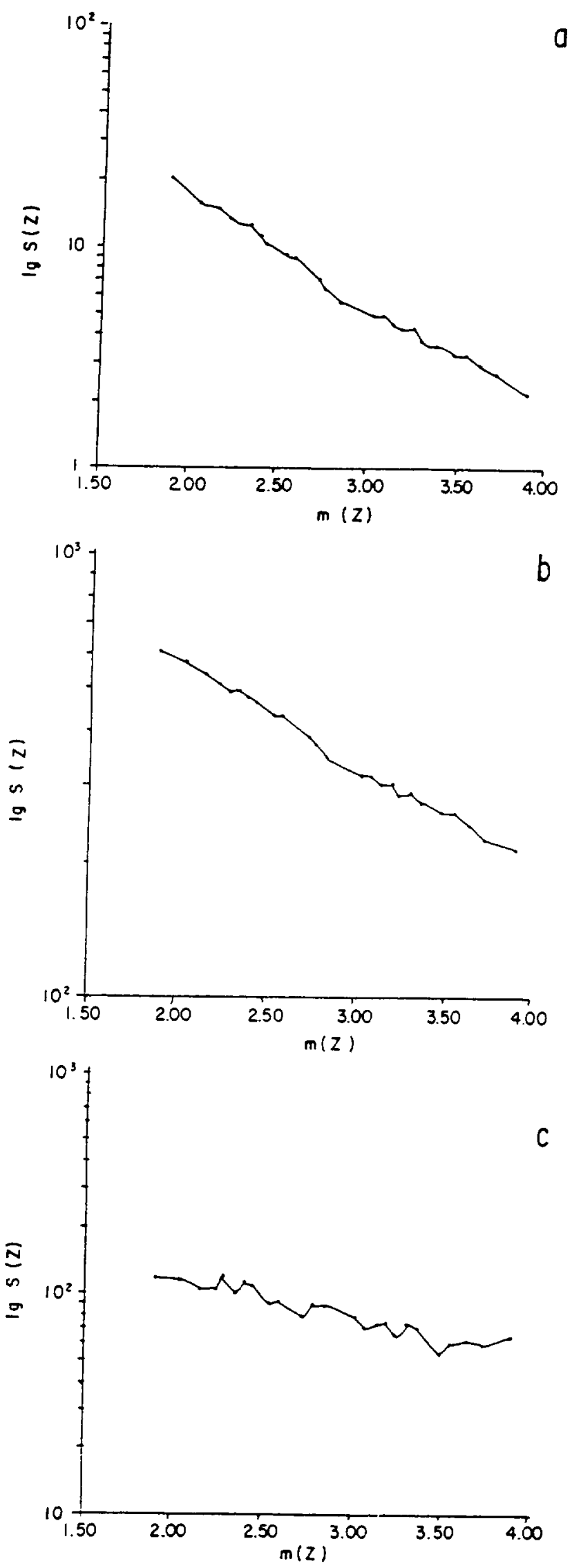

Figure 2. Examples of "Langley plots" (or "Bouguer lines") taken in Mexico City on April 12,1992, for (a) UV at $1=377$ $\mathrm{nm}$; (b) visible at $\mathrm{l}=545 \mathrm{~nm}$; and (c) NIR at $\mathrm{l}=814 \mathrm{~nm}$. of the Sun's azimuth does not exceed $20^{\circ}$ during this measurement time. As a result, there is no significant azimuthal influence on the observational data.

The spectral optical depth $\tau(\lambda)$ is composed of four parts: (1) molecular (Rayleigh) scattering, (2) molecular absorption, (3) aerosol scattering, and (4) aerosol absorption. If one subtracts the molecular (Rayleigh) scattering part from $t(l)$, the remainder, the so-called "reduced SOD," characterizes aerosol attenuation (scattering and absorption) and molecular absorption.

It is common to apply the Angström turbidity formula [Angström, 1961; Iqbal, 1983] to the analysis of aetosol measurements:

$$
\tau(\lambda)=\beta \lambda^{-\infty},
$$

where $\beta$ is the so-called Angström turbidity coefficient (note that this coefficient is equal to $\tau(\lambda=1 \mu \mathrm{m})$ ). Angstrom [1961] suggested $\propto=1.3 \pm 0.5$ as an average value and showed that if a Junge size distribution $N(r)$ of aerosol particles is assumed,

$$
N(r)=N_{0} r^{-v},
$$

where $r$ is the particle radii and $N_{0}$ and $v$ are constants, then an exact relationship between $\propto$ in equation (4) and $v$ in equation (5) exists, namely,

$$
v=\propto+2
$$

Therefore assuming that the aerosol size distribution is Jungian, the slope of the averaged size distribution can be estimated from the spectral dependence of the optical thickness measurements.

Unfortunately, this Angstrom formula approach does not represent the observations well, because it is based only on Mie scattering by the large particles in the size distribution. Other problems which limit the applicability of this approach are: (1) the absorption of light by aerosol particles is not accounted for, (2) most size distributions are multimodal; and (3) giant particles (i.e., strong haze, fog) tend to scatter light almost neutrally (i.e., wavelength independent). As a result, an alternative formula has been suggested [e.g., Shifrin and Minin, 1957] of the form

$$
\tau(\lambda)=C+A \lambda^{-\infty},
$$

where $\mathrm{C}$ and $\mathrm{A}$ are constants. Using this approach, the Angstrom turbidity coefficient, computed as $b=t(1)$ at $\lambda=1 \mu \mathrm{m}$, is

$$
\beta=C+A
$$

In equation (7), $\mathrm{C}$ is the contribution due either to absorption by all aerosol particles or to scattering by giant particles. Assuming $C$ to be due only to absorption, the spectral singlescattering albedo $\varpi_{0}(\lambda)$ may be estimated for aerosol particles as

$$
\tilde{\omega}_{0}(\lambda) \geq 1-\frac{C}{\tau(\lambda)}
$$




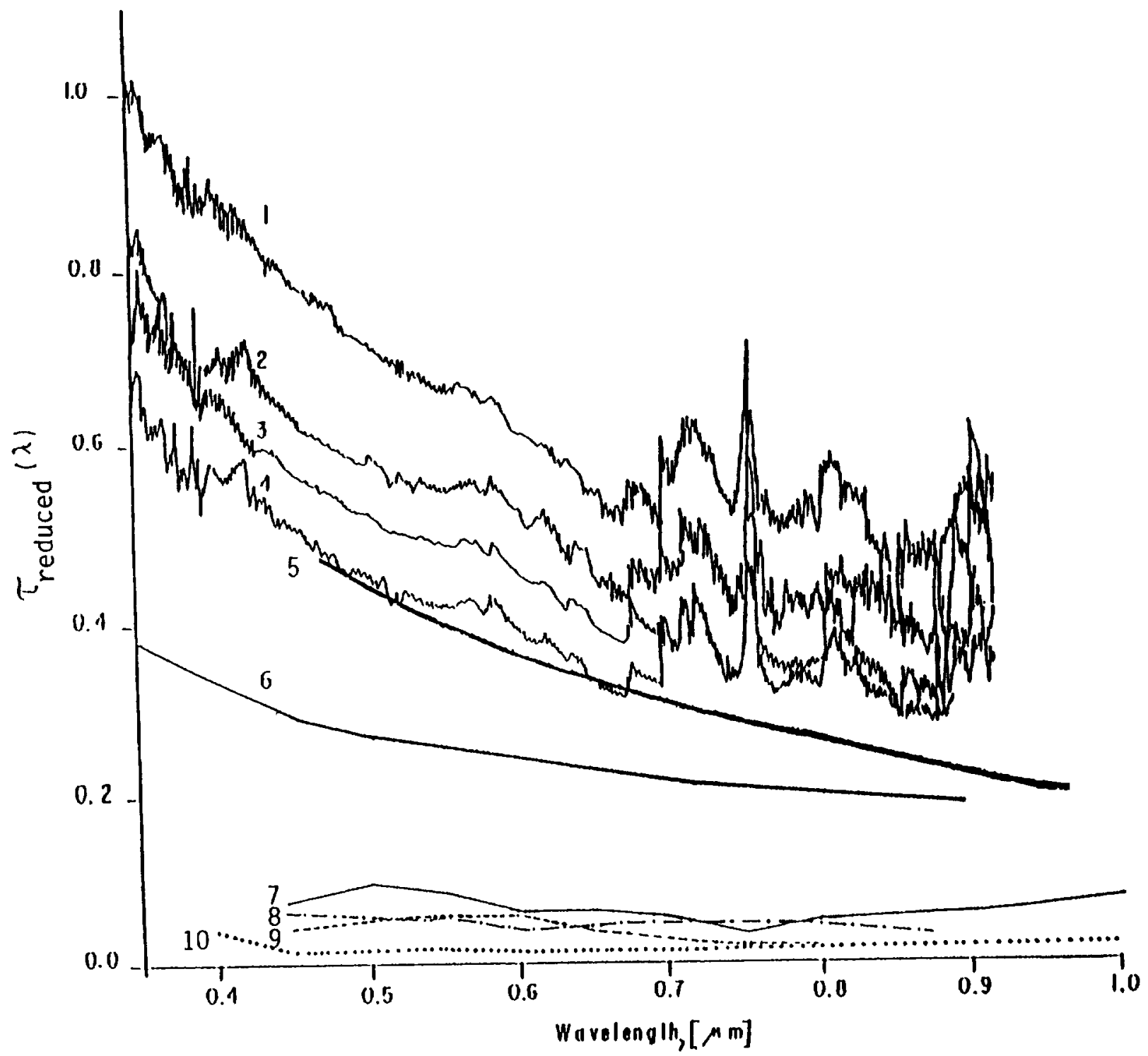

Figure 3. Aerosol Spectral Optical Depth (SOD) in Mexico City in April 1992. Number 1, April 14; 2 , April 12, 3, April 16, 4, April 15, 5, WMO Standard Radiation Atmosphere (1986), 6, SOD in the Elter[Kondratyev et al., 1965; Kondratyev ed., 1969] at different heights above sea level, 7, $45 \mathrm{~m} ; 9,3410 \mathrm{~m}$, $10,3700 \mathrm{~m}$, and 8, SOD measured in Tucson, Arizona [Box et al., 1981] in May 1977.

If scattering by very large aerosol particles cannot be neglected, then the estimate in equation (9) will be reduced; in such cases, equation (9) is considered as a minimum estimate.

\section{Results}

\subsection{Aerosol Spectral Optical Depths}

Reduced spectral optical depth (total spectral optical depths minus Rayleigh depths) observations taken in Mexico City on April 12,14, 15, and 16 are shown in Figure 3 (curves 1-4). Absorption bands of ozone, water vapor, and oxygen are recognized. The spectral signature in the UV-blue spectral range probably is caused by the absorption by nitrogen dioxide, often present in large concentrations in urban regions. Values of aerosol SOD measured in Mexico City are much larger than those found in most other regions of the world [e.g., Kondratyev et al., 1965, 1974a, b; Box et al., 1981]. Curves labeled $5-10$ in Figure 3 are used as reference spectra of typical background values found in other regions of the globe. Curves 7 , 9 , and 10 were obtained in unpolluted regions of Russia at 45 $\mathrm{m}, 3410 \mathrm{~m}$, and $3700 \mathrm{~m}$ above sea level. Curve 8 was measured in Tucson, Arizona, in May 1977 [Box et al., 1981]. Observations made in different years in Tucson have similar values [Shaw et al., 1973; King et al., 1978; King, 1982]. Curve 5 shows continental aerosol SOD values according to the Standard Radiation Atmosphere [World Meteorological Organization (WMO), 1986]; and, finally, curve 6 represents the results of SOD calculations made using the polluted aerosol model of Elterman [1968] which is similar to the U.S. Standard Atmosphere. This model assumes that the aerosol concentration corresponds to a visibility of $25 \mathrm{~km}$, which is con- 
Table 2 Solution of equation (7) Using the Method of Variation of Parameter $\alpha_{2}$

\begin{tabular}{|c|c|c|c|c|}
\hline$\alpha_{2}$ & $\mathrm{C}_{2}$ & $\mathbf{A}_{2}$ & $\mathrm{R}_{2}$ & $s_{2}$ \\
\hline 0.10 & -4.524 & 4.790 & 0.9728 & 0.0948 \\
\hline 0.20 & -1.987 & 2.259 & 0.9758 & 0.0845 \\
\hline 0.30 & -1.141 & 1.419 & 0.9789 & 0.0739 \\
\hline 0.40 & -0.719 & 1.003 & 0.9819 & 0.0636 \\
\hline 0.50 & -0.466 & 0.755 & 0.9845 & 0.0546 \\
\hline 0.60 & -0.297 & 0.592 & 0.9869 & 0.0464 \\
\hline 0.70 & -0.176 & 0.477 & 0.9891 & 0.0386 \\
\hline 0.80 & -0.086 & 0.392 & 0.9910 & 0.0319 \\
\hline 0.90 & -0.016 & 0.327 & 0.9926 & 0.0263 \\
\hline 1.00 & 0.041 & 0.276 & 0.9940 & 0.0216 \\
\hline 1.10 & 0.087 & 0.235 & 0.9950 & 0.0180 \\
\hline 1.20 & 0.125 & 0.201 & 0.9958 & 0.0151 \\
\hline 1.30 & 0.158 & 0.174 & 0.9962 & 0.0136 \\
\hline 1.40 & 0.186 & 0.151 & 0.9965 & 0.0127 \\
\hline 1.50 & 0.210 & 0.132 & 0.9963 & 0.0132 \\
\hline 1.60 & 0.232 & 0.115 & 0.9960 & 0.0145 \\
\hline 1.70 & 0.251 & 0.101 & 0.9952 & 0.0172 \\
\hline 1.80 & 0.268 & 0.089 & 0.9943 & 0.0206 \\
\hline 1.90 & 0.283 & 0.079 & 0.9930 & 0.0251 \\
\hline 2.00 & 0.297 & 0.069 & 0.9915 & 0.0306 \\
\hline 2.10 & 0.309 & 0.061 & 0.9898 & 0.0369 \\
\hline 2.20 & 0.321 & 0.055 & 0.9877 & 0.0443 \\
\hline 2.30 & 0.331 & 0.048 & 0.9854 & 0.0525 \\
\hline 2.40 & 0.341 & 0.043 & 0.9829 & 0.0616 \\
\hline 2.50 & 0.350 & 0.038 & 0.9801 & 0.0715 \\
\hline 2.60 & 0.358 & 0.034 & 0.9771 & 0.0823 \\
\hline 2.70 & 0.366 & 0.031 & 0.9738 & 0.0937 \\
\hline 2.80 & 0.374 & 0.027 & 0.9704 & 0.1059 \\
\hline 2.90 & 0.381 & 0.024 & 0.9668 & 0.1186 \\
\hline 3.00 & 0.387 & 0.022 & 0.9629 & 0.1321 \\
\hline 3.10 & 0.394 & 0.019 & 0.9589 & 0.1461 \\
\hline 3.20 & 0.399 & 0.017 & 0.9547 & 0.1606 \\
\hline 3.30 & 0.405 & 0.016 & 0.9504 & 0.1757 \\
\hline 3.40 & 0.410 & 0.014 & 0.9459 & 0.1911 \\
\hline 3.50 & 0.416 & 0.013 & 0.9412 & 0.2070 \\
\hline 3.60 & 0.420 & 0.011 & 0.9365 & 0.2231 \\
\hline 3.70 & 0.425 & 0.010 & 0.9316 & 0.2397 \\
\hline 3.80 & 0.430 & 0.009 & 0.9265 & 0.2566 \\
\hline 3.90 & 0.434 & 0.008 & 0.9214 & 0.2736 \\
\hline 4.00 & 0.438 & 0.007 & 0.9163 & 0.2908 \\
\hline
\end{tabular}

sidered to be moderate pollution. The values of SOD of the polluted atmosphere in Mexico City are significantly larger, representing visibilities of about $3 \mathrm{~km}$.

Note the spectral dependence of the curves shown in Figure 3. As the optical thickness increases, the slopes of the curves likewise increase. Aerosol absorption typically is large for the type of particles typically found in the polluted urban envi- ronment. Therefore when the aerosol concentrations are low, the role of aerosol absorption in the attenuation of light dominates over scattering by aerosol ensembles. Then the spectral dependence of aerosol optical depth follows closely the dependence of the imaginary part of the aerosol refractive index. For many aerosols (salts, soils, and soot) this spectral dependence is nearly neutral in the $0.4-$ to $1.0-\mu \mathrm{m}$ spectral range. In 


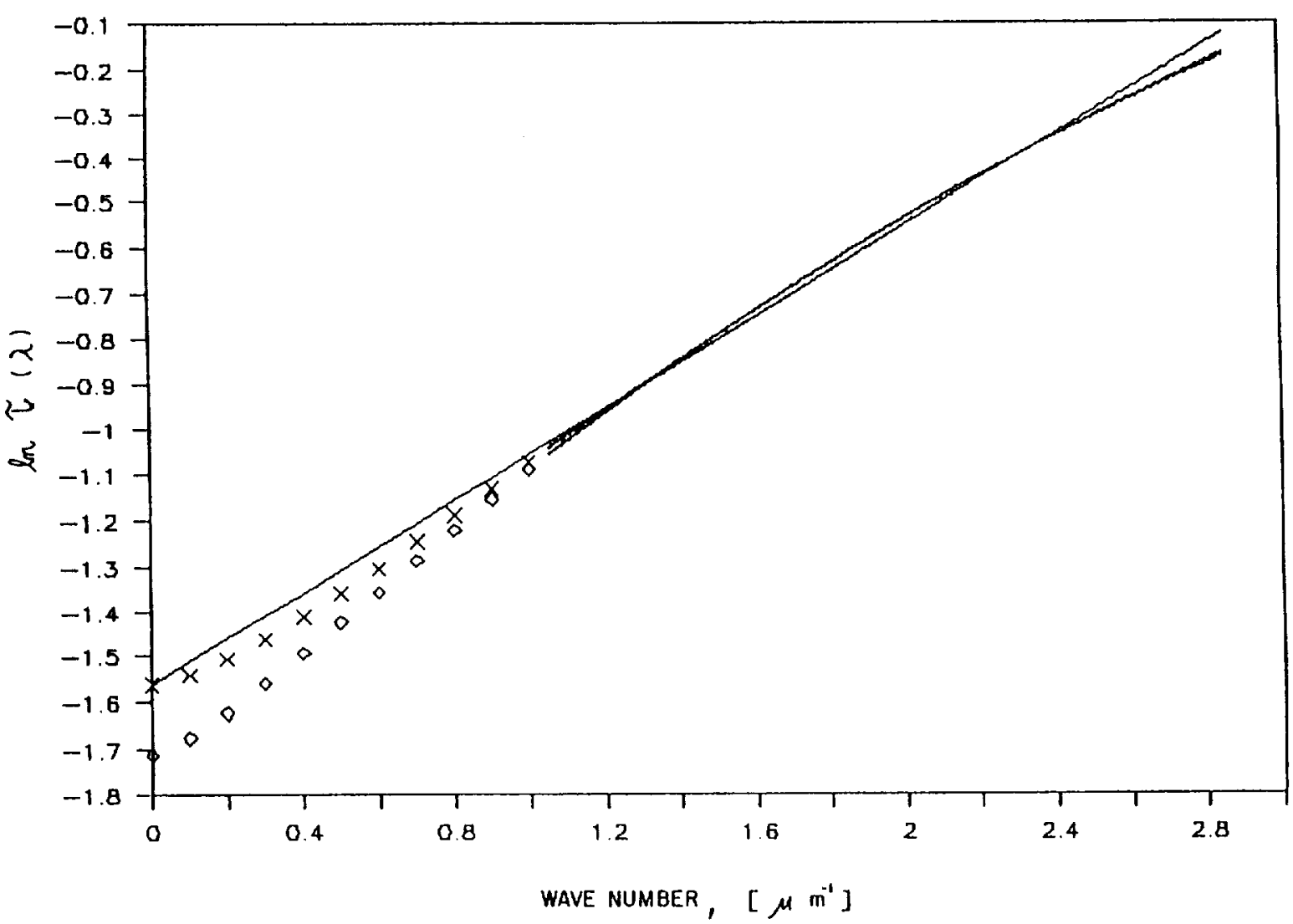

Figure 4. Comparison of different approximations of SOD (explanations are given in the text).

such cases, the absolute values of SOD generally do not exceed $\tau=0.1-0.2$. Such is the case for curves 6-9 in Figure 3 . For curves 5 and 6 , with an optical thickness of about $0.2-$ 0.55 , scattering becomes important; hence the spectral dependence becomes nonneutral. As seen in curves 1-6, the spectral signature is due to the increasing role of scattering of light in optically thicker aerosol layers, especially for wavelengths in the range of $0.35-0.70 \mu \mathrm{m}$. In the highly polluted Mexico City atmosphere the amount of radiation attenuated by aerosols is of the same order of magnitude as that scattered by the molecular atmosphere (i.e., Rayleigh scattering).

As noted above, during the processing of the measurements, so-called "Langley plots" (or "Bouguer lines") were computed (see Figure 2). These are regression lines of the logarithm of measured intensity against optical path length (i.e., air mass). The correlation coefficient obtained from this analysis was found to be greater than 0.95 , indicating a relatively low level of experimental error. However, one obtains reliable values of SOD only when the optical parameters of the Earth's atmosphere do not change during the observational period. Therefore the measurements were examined by applying statistical processing methods; for example, data were rejected with large standard deviations. Using the Pierson $\chi^{2}$-criteria (confidence level of 0.995 ), all measurements with large errors in determination of the SOD were rejected. Rejected measurements were those which had only a few observations or those in which there were only a few measurements at different solar zenith angles (i.e., limited change of optical path length intervals). Then, using the Student $t$-criteria, measurements whose extrapolated direct solar radiation fluxes were out of the confidence level of 0.995 also were rejected. The Fisher F-criteria were applied to the ratio of interseries deviation to a random one as a final rejection test (confidence level of 0.995). As a result, half of the measurements were rejected. This should be expected, because the optical properties of the morning Mexico City atmosphere often do not remain stable for extended periods of time.

\subsection{Spectral Dependencies of Measured Optical Depth}

The attenuation of light by aerosol particles is caused by both scattering and absorption processes. Usually it is impossible to separate one effect from the other, hence Angstrom [1961] suggested the use of the Angstrom turbidity formula, given by equation (4). This equation expresses the spectral dependence of optical depth versus wavelength only in cases of weak air pollution (refer to the parameters of this equation as $\alpha_{1}$ and $C_{1}=\beta$ ). For the strongly polluted atmosphere of Mexico City it is necessary to use equation (7) (refer to these three parameters as $\alpha_{2}, C_{2}$, and $A_{2}$ ). Note that this equation is nonlinear. To determine all three coefficients simultaneously, one of these parameters is fixed and the other two are computed. It is usually most convenient to fix the power $\alpha$ in equation (7), since it is known that this parameter may vary only between 0 and 4 . The calculations are performed in the following way: Using the least squares method, the solution is found for fixed values of $\alpha$, varying from 0 to 4 , with the step size equal to 0.1 . That solution is chosen which has the highest correlation coefficient (or the lowest standard deviation). Of course, differences between the alternative solutions 
Table 3 Results of the Approximation of SOD Taken in Mexico City in 1992

\begin{tabular}{|c|c|c|c|c|c|c|c|c|c|c|c|}
\hline \multirow[b]{2}{*}{$\begin{array}{l}\text { Date, } \\
\text { Morning } \\
\text { Series }\end{array}$} & \multicolumn{3}{|c|}{ Angström Formula } & \multicolumn{4}{|c|}{ Formula (7), Variation of $\alpha$} & \multicolumn{4}{|c|}{$\begin{array}{c}\text { Formula (b), Determination of } \\
\mathrm{C}_{3} \text { Using (11) }\end{array}$} \\
\hline & $\alpha_{1}$ & $\begin{array}{l}C_{1} \\
\times 10\end{array}$ & $\begin{array}{r}\mathrm{S}_{1} \\
\times 10^{2}\end{array}$ & $\alpha_{2}$ & $\begin{array}{l}\mathrm{C}_{2} \\
\mathrm{x} 10\end{array}$ & $\begin{array}{l}\mathrm{A}_{2} \\
\times 10\end{array}$ & $\begin{array}{l}\mathrm{S}_{2} \\
\times 10^{2}\end{array}$ & $\alpha_{3}$ & $\begin{array}{l}\mathrm{C}_{3} \\
\times 10\end{array}$ & $\begin{array}{l}\mathrm{A}_{3} \\
\mathrm{x} 10\end{array}$ & $\begin{array}{c}\mathrm{S}_{3} \\
\times 10^{2}\end{array}$ \\
\hline May 01 & 1.25 & 3.12 & 9.5 & 1.84 & 1.96 & 1.45 & 4.8 & 1.76 & 1.83 & 1.59 & 5.0 \\
\hline May 16 & 1.15 & 2.95 & 4.1 & 1.54 & 1.62 & 1.64 & 2.8 & 1.69 & 1.85 & 1.39 & 3.0 \\
\hline May 21 & 1.05 & 2.85 & 4.7 & 1.73 & 2.14 & 1.07 & 2.3 & 1.57 & 1.95 & 1.24 & 2.5 \\
\hline May 28 & 1.40 & 1.94 & 5.3 & 1.78 & 1.06 & 1.16 & 3.9 & 1.86 & 1.12 & 1.06 & 4.0 \\
\hline $\begin{array}{l}\text { Average } \\
\text { (a) }\end{array}$ & 1.22 & 2.69 & 4.7 & 1.75 & 1.71 & 1.29 & 1.8 & 1.72 & 1.69 & 1.32 & 3.8 \\
\hline April 12 & 0.87 & 3.30 & 3.7 & 1.06 & 1.06 & 2.35 & 3.4 & 1.57 & 2.03 & 1.19 & 4.5 \\
\hline April 14 & 0.88 & 4.00 & 5.6 & 0.88 & 0 & 4.00 & 5.6 & 1.57 & 2.70 & 1.49 & 12.3 \\
\hline May 25 & 1.02 & 2.30 & 4.2 & 1.23 & 0.77 & 1.66 & 4.0 & 1.61 & 1.66 & 0.96 & 4.6 \\
\hline $\begin{array}{l}\text { Average } \\
\text { (b) }\end{array}$ & 0.90 & 3.23 & 11.0 & 0.90 & 0 & 3.23 & 1.1 & 1.59 & 2.13 & 1.21 & 7.1 \\
\hline May 15 & 0.69 & 3.40 & 14.4 & \multicolumn{4}{|c|}{ solution not found } & 1.28 & 2.91 & 1.07 & 12.0 \\
\hline May 27 & 0.67 & 3.60 & 8.9 & 0.67 & 0 & 3.60 & 8.9 & 1.61 & 2.22 & 1.75 & 18.0 \\
\hline June 14 & 0.60 & 3.23 & 3.5 & \multicolumn{4}{|c|}{ solution not found } & 1.34 & 1.52 & 0.78 & 1.5 \\
\hline $\begin{array}{l}\text { Average } \\
\text { (c) }\end{array}$ & 0.60 & 3.57 & 2.4 & 0.80 & 1.35 & 2.31 & 2.3 & 1.41 & 2.22 & 1.20 & 10.5 \\
\hline $\begin{array}{l}\text { Average } \\
(\mathrm{a}-\mathrm{c})\end{array}$ & 0.92 & 3.12 & 2.5 & 1.38 & 1.81 & 1.55 & 1.3 & 1.45 & 1.98 & 1.25 & 1.3 \\
\hline April 25 & 0.16 & 18.5 & 17.3 & \multicolumn{4}{|c|}{ solution not found } & 0.72 & 19.6 & 1.43 & 14.8 \\
\hline May 02 & 0.04 & 8.45 & 23.7 & \multirow{2}{*}{\multicolumn{2}{|c|}{$\begin{array}{l}\text { solution } \\
\text { solution }\end{array}$}} & not found & & 1.05 & 4.81 & 0.80 & 28.6 \\
\hline May 13 & 0.13 & 9.69 & 13.8 & & & not found & & 0.65 & 6.20 & 1.72 & 13.8 \\
\hline $\begin{array}{l}\text { Average } \\
\text { (d) }\end{array}$ & 0.13 & 12.2 & - & \multicolumn{4}{|c|}{ solution not found } & 0.81 & 10.2 & 1.32 & 19.1 \\
\hline
\end{tabular}

must be statistically significant. Only in cases of strong pollution is it statistically reliable to apply this approach.

Table 2 illustrates how the method is applied in practice. The data used are the average of observations taken in Mexico City during the whole observational period of 1992 . In this case, the maximum correlation coefficient $\mathrm{R}_{2}$ corresponds to the value of $\alpha=1.4$ with the minimum standard deviation $s_{2}=$ 0.0127 . To achieve higher accuracy, the calculations may be repeated in a narrower range of $\alpha$ with the step size equal to 0.01 . Note that a solution with $C_{2}=0$ corresponds to the Angström turbidity formula, equation (4). Such a solution would correspond to the value of $\alpha=0.925$, with the value of Angstrom turbidity coefficient $\mathrm{A}_{2}=0.31$ and the standard deviation of 0.025 , which is twice as large as in the previous case. This means that had the Angstrom turbidity formula (equation (4)) been used for the approximation of the experi- mental data, a value of $\alpha=0.925$ would have resulted instead of the correct value of $\alpha=1.4$. Note also that the Angstrom turbidity coefficient is equal to 0.31 ; this value is about $10 \%$ low, because equation ( 7 ) yields $\mathrm{C}_{2}+\mathrm{A}_{2}=0.34$. However, once again note that the approach of varying parameter $\alpha_{2}$ is applicable only in cases of strong air pollution (when $\tau(\lambda=0.5$ $\mu \mathrm{m}) \geq 0.6$ ).

For cases of weaker air pollution, another approach may be used. One may assume an exponential form of $t(1)$ :

$$
\tau(\lambda)=c_{3} e^{\alpha_{3} / \lambda}
$$

This equation is linearized taking its logarithm:

$$
\ln t(1)=\ln C_{3}+a_{3} / 1
$$

In this case, the parameter $\mathrm{C}_{3}$ and $\mathrm{a}_{3}$ are determined using the 
Table 4: Characteristics of the Atmospheric Turbidity in Mexico City in April-June 1992

\begin{tabular}{lcccc}
\hline \multicolumn{1}{c}{ Groups of Days } & $\begin{array}{c}\mathbf{C}_{\mathbf{1}} \text { (Angstrom } \\
\text { Formula) }\end{array}$ & $\mathbf{A}_{\mathbf{2}}+\mathbf{C}_{\mathbf{2}}$ & $\mathbf{A}_{\mathbf{3}}+\mathbf{C}_{\mathbf{3}}$ & $\mathbf{0 . 5 x \tau ( \lambda = 0 . 5 \mu \mathrm { m } )}$ \\
\hline Cloudless days, 1 gr. (a) & 0.27 & 0.30 & 0.30 & 0.31 \\
Cloudless days, 2 gr. (b) & 0.32 & 0.32 & 0.33 & 0.31 \\
Days with haze (c) & 0.36 & 0.37 & 0.34 & 0.27 \\
All cloudless days (a-c) & 0.31 & 0.34 & 0.32 & 0.30 \\
\hline
\end{tabular}

least squares method. Then if the value of $C_{3}$ is known, it is casy to linearize equation (7) by taking its logarithm; in particular,

$$
\ln \left[\tau(\lambda)-C_{3}\right]=\ln A_{3}-\alpha_{3} \ln \lambda
$$

Parameters $A_{3}$ and $\alpha_{3}$ are computed using the leastsquares method. Mathematically, this means that the approximation is based upon equation (7), but it is restricted to pass through the point $\left(0, C_{3}\right)$ on the plot of $\ln \tau(\lambda)$ versus $1 / \lambda$ (see equation (11)).
Figure 4 illustrates the errors which occur using this approach. Again we use the averaged values of $\tau(\lambda)$ calculated for all of the series of measurements taken in Mexico City in 1992. This averaged curve and its extension to $1 / \lambda \rightarrow 0$, using the method of variation of $\alpha$, is shown by squares in Figure 4 . The exponential approximation for the spectral range of observations $(0.35-0.95 \mu \mathrm{m})$ and its corresponding extension to $1 / \lambda \rightarrow 0$ is shown by the solid line. The approximation using equation ( 7 ) with the constant $\mathrm{C}_{3}$, determined using equation (11), is shown by the crosses in Figure 4 . Within the spectral range of the measurements, differences between

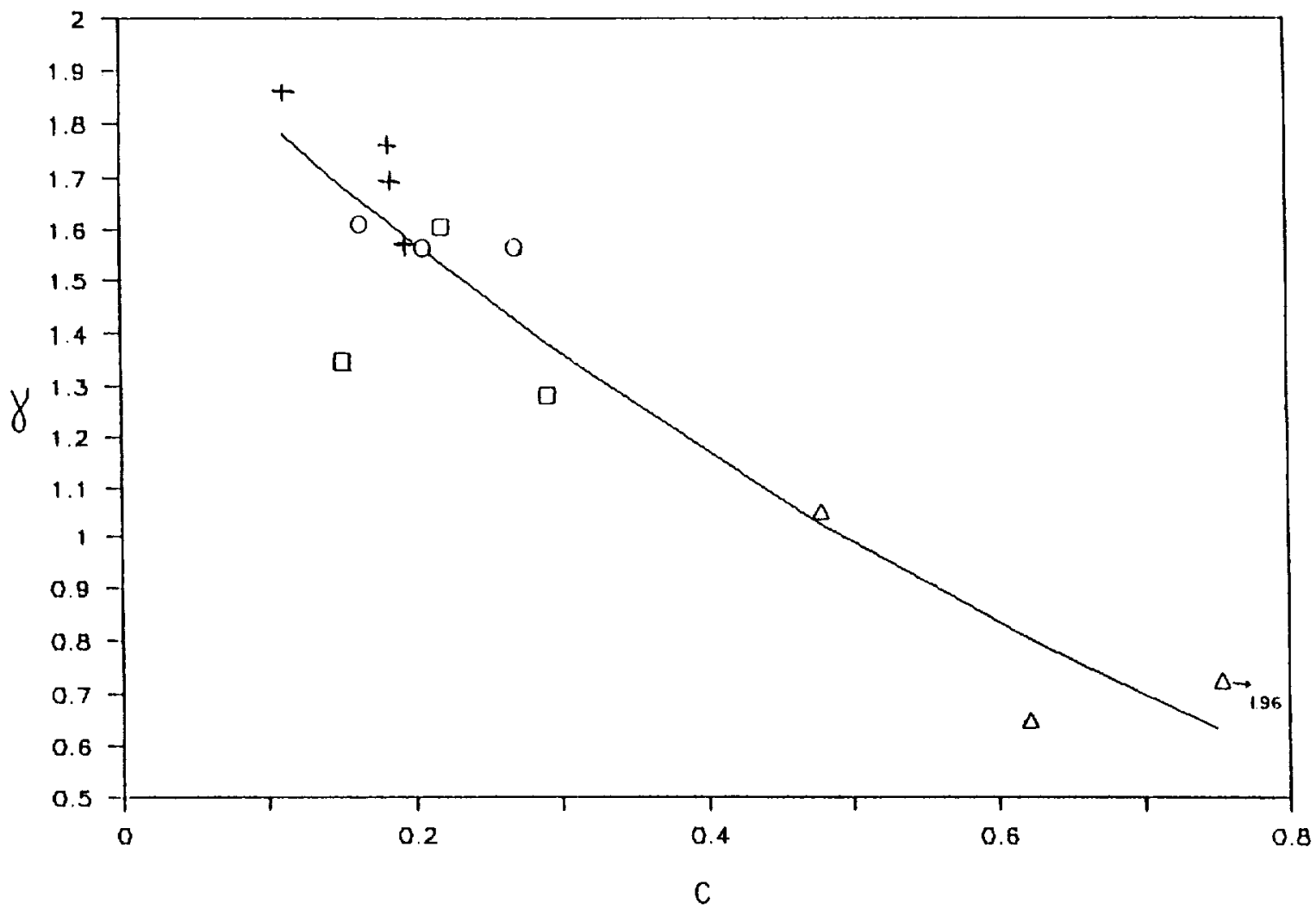

Figure 5. Dependence of the parameter a versus the parameter $C$ : plus, clear days, case "a"; circle, clear days, case " $b$ "; square, days with haze; and triangle, days with cirrus clouds. 

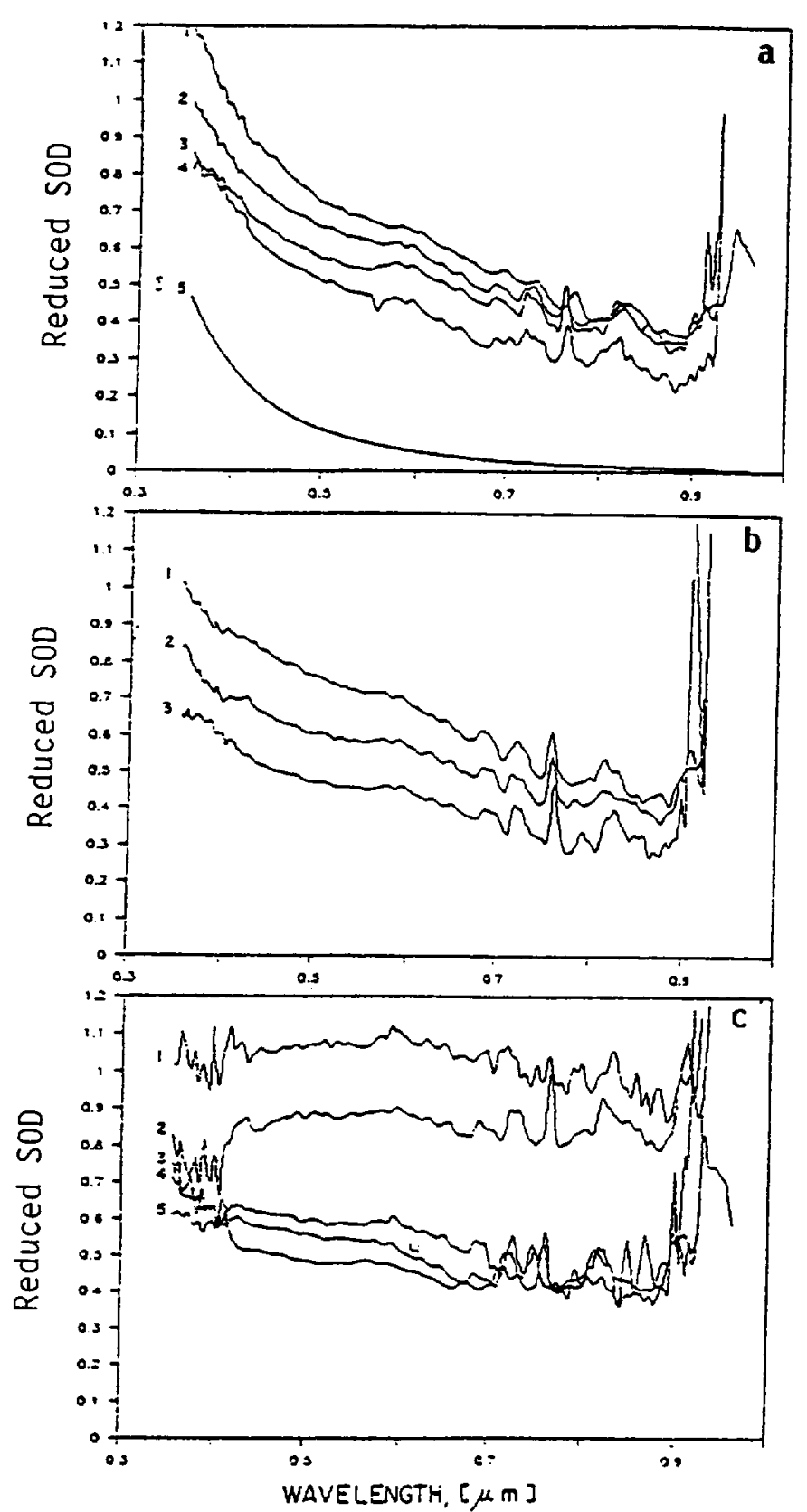

Figure 6. Aerosol SOD observed in Mexico City in 1992 divided into groups according to the values of the parameter a (the order of the dates from the top to the bottom: (a) May 1, $16,21,28$, and Rayleigh; (b) April 14, 12, and May 25; (c) May 13, 2, 27, 15, and June 14 (morning series).

these approaches are not statistically significant; the curves effectively coincide. The difference between $\mathrm{C}_{2}=0.181$ and $C_{3}=0.198$ is about $9 \%$, and the value of $\alpha$ varies from 1.40 to 1.45 , about a $3 \%$ difference. Taking into account the fact that the observational errors are of the order of several percent, these differences may be considered as insignificant.

The results of the different approximations of the aerosol spectral optical depths measured in Mexico City are given in Table 3. In all cases the Angstrom turbidity formula provides low values of both the parameter $\alpha$ and the Angstrom turbidity coefficient. The method of variation of the parameter $\alpha$ provides a solution only in cases of high air pollution, while the approach of determining the parameter $C_{3}$ from the exponential approximation works in all cases under consideration.

For various degrees of atmospheric turbidity, Angstrom defined the following values of turbidity coefficient: clean, 0.0 ; clear, $\approx 0.1$; turbid, $\approx 0.2$; and very turbid, $\approx 0.4$. The corresponding visibilities are $340 \mathrm{~km}, 28 \mathrm{~km}, 11 \mathrm{~km}$, and $<$ $\mathrm{km}$, respectively. Table 4 gives the value of the turbidity coefficient determined using the different approaches. Values of turbidity coefficient range from 0.27 to 0.37 , with visibilities in the range of about $7 \mathrm{~km}$ to $13 \mathrm{~km}$, corresponding to a very turbid atmosphere. Visibilities were observed to be about 3 $\mathrm{km}$ or less, which coincide (within the limits of experimental error) with the estimate made using Angstrom turbidity coefficient.

The parameters $\alpha_{3}$ and $C_{3}$ are related, as shown in Figure 5. The solid line is a power law which is computed using the least squares method.

The spectrophotometric measurements may be divided into four groups. Some polluted, cloudless days are found to have a strong dependence of $\tau$ versus $\lambda$, with values ranging from $1.70<\alpha<1.85$. Other polluted, cloudless days are found with a weaker dependence of $\tau$ versus $\lambda$, with $1.55<\alpha<$ 1.65. For days with haze, there is a still weaker dependence of $\tau$ versus $\lambda$, with values of $1.25<\alpha<1.60$. Finally, when cirrus clouds are present, there is nearly neutral dependence of $\tau$ versus $\lambda$, with values of $0.65<\alpha<1.05$. These differences in the values of $\alpha$ may be caused by several reasons.
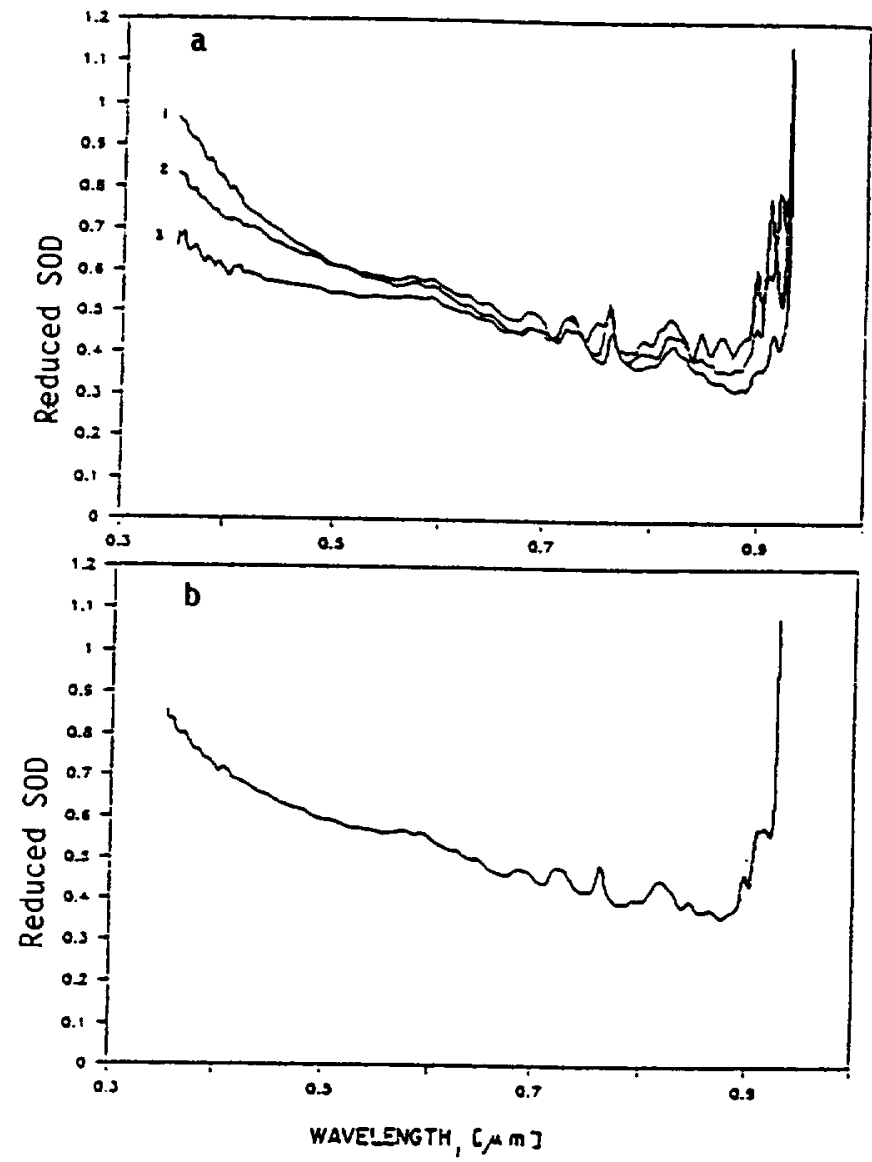

Figure 7. Aerosol SOD observed in Mexico City in 1992: (a) averaged according groupings in Figure 6; (b) averaged over all the observations on clear days. 


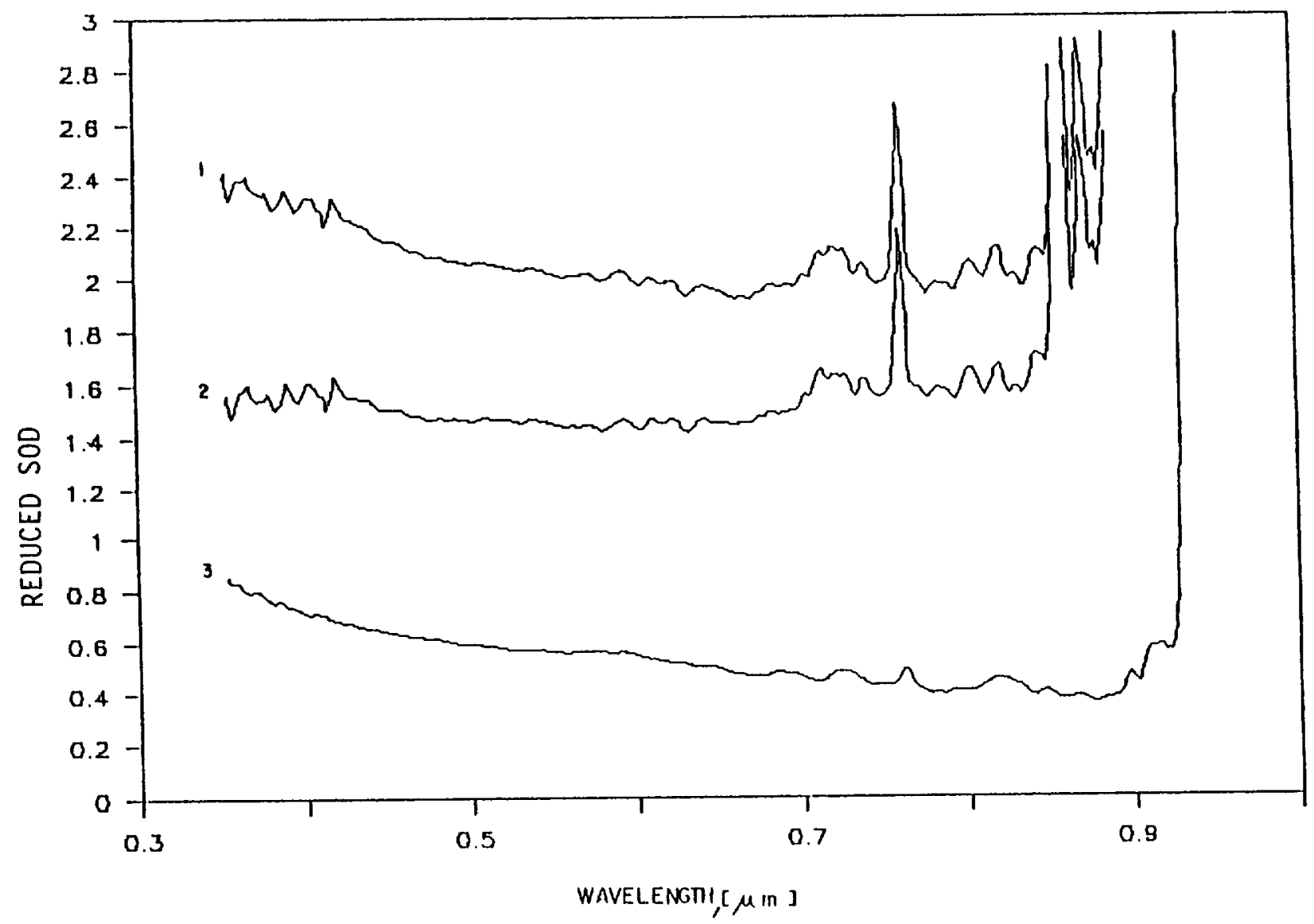

Figure 8. SOD of cirrus clouds observed in Mexico City on April 24, 1992: number 1, observed SOD; 2, average curve for all cloudless days (Figure 7d); and 3 SOD of only cirrus clouds.

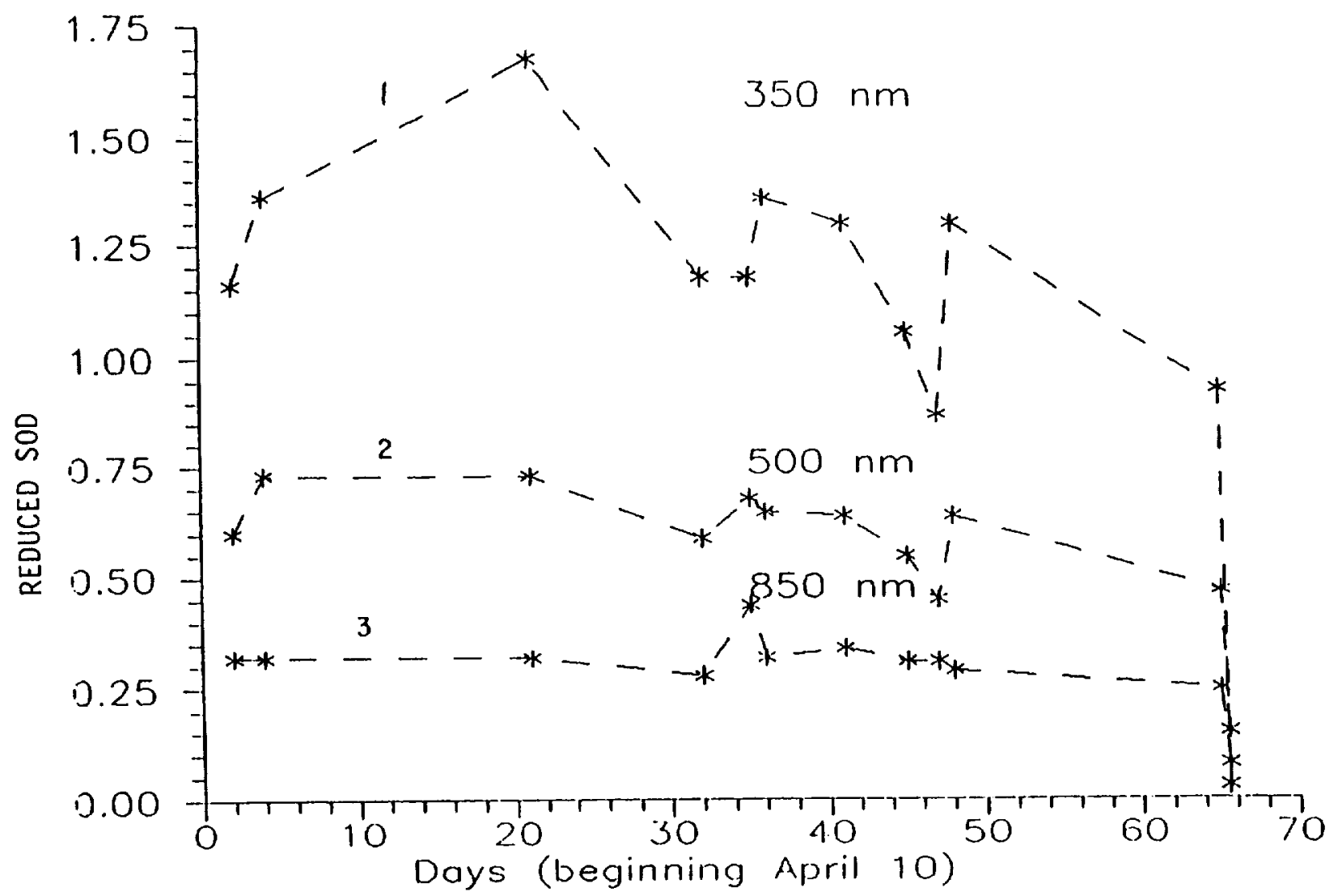

Figure 9. Temporal variations of aerosol SOD at three wavelengths: $350 \mathrm{~nm}, 500 \mathrm{~nm}$, and $850 \mathrm{~nm}$ for the period beginning April 10, 1992. 


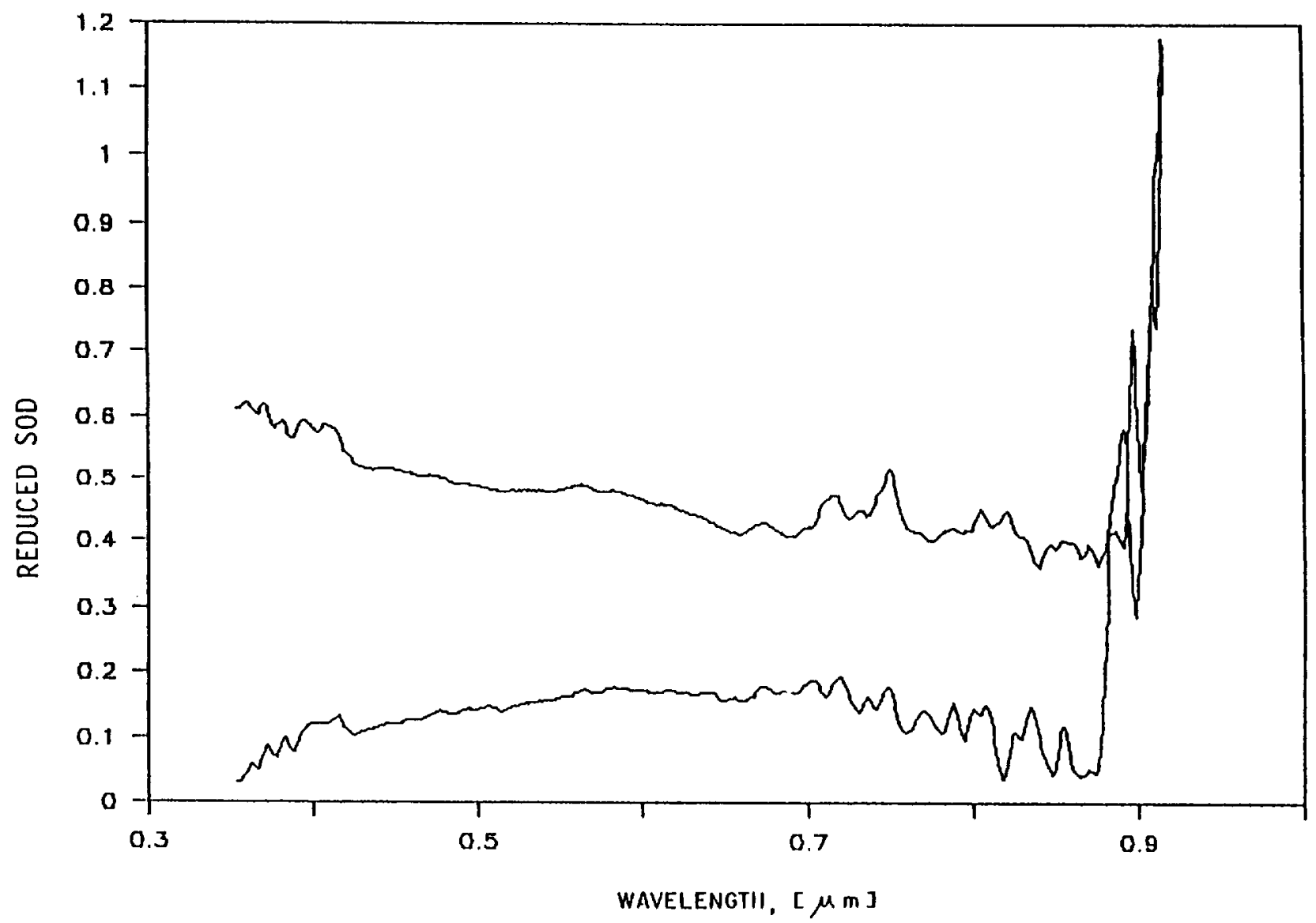

Figure 10. Comparison of SOD measured in Mexico City on June 14 in the morning (top curve) and in the evening (bottom curve).

First, for high relative humidity, the aerosol particles may become covered by water, decreasing the absorption but increasing scattering in the forward direction (e.g., detected as the presence of a haze). Second, the aerosol particles may coagulate, resulting in a variation in size distribution. Increasing

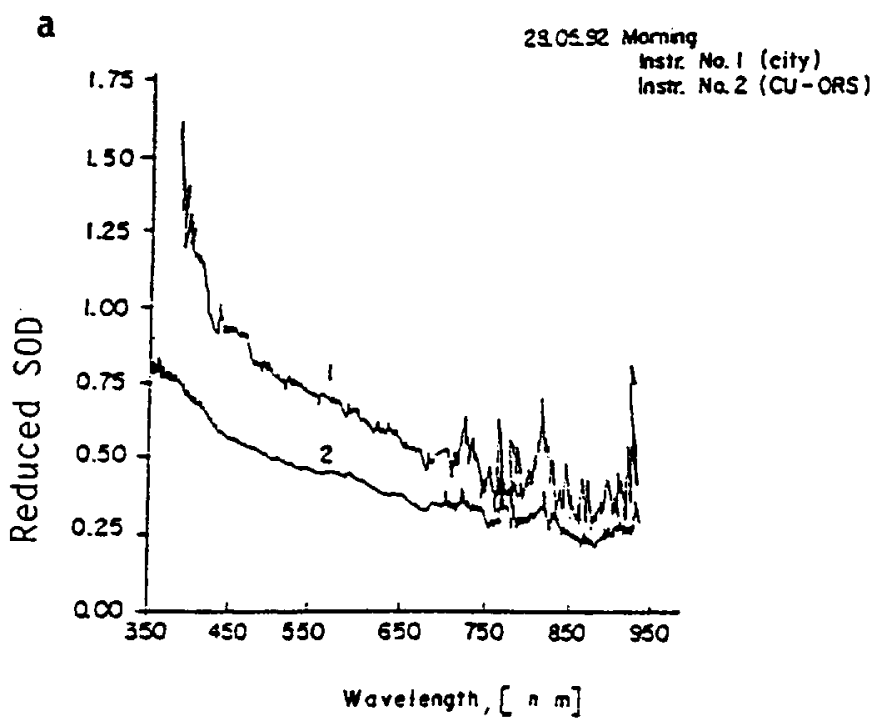

the numbers of large particles will produce a decrease in the slope of the $\tau$ versus $\lambda$ dependence. Another factor also needs to be considered. Multiple scattering increases with increasing particle concentration (i.e., increasing $\tau$ ), changing the slope of the $\tau$ versus $\lambda$ dependence. All of these factors may

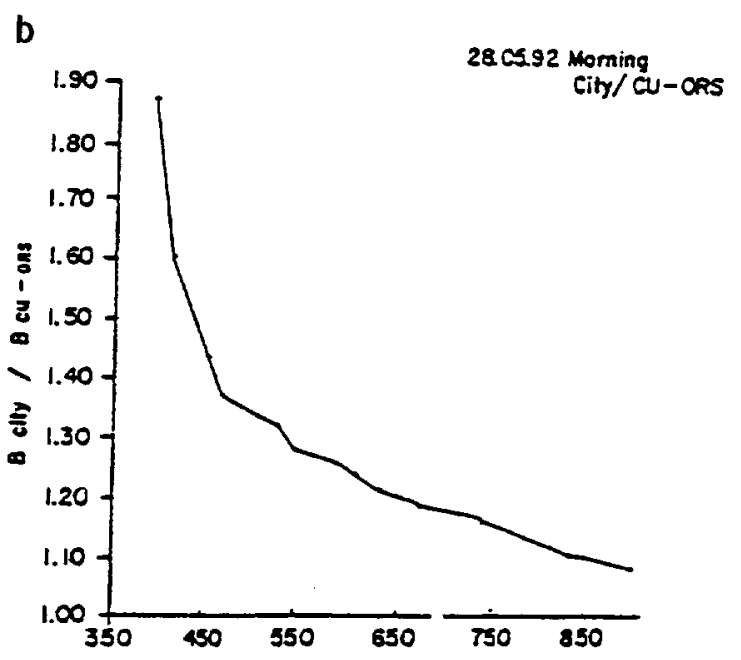

Figure 11. (a) Comparison of aerosol SOD measured on May 28: number 1 in the center of Mexico City; and 2 at the territory of Cd. Universitaria; (b) the ratio of intensities of direct solar radiation. 


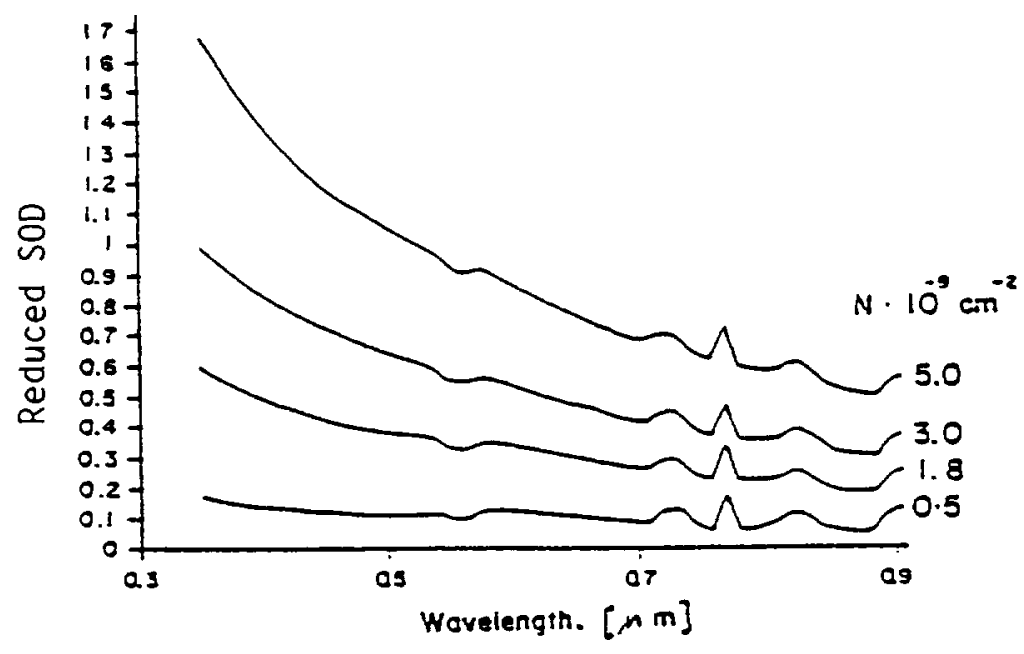

Figure 12. Calculated aerosol SOD for different amounts of aerosol particles $\left(0.5,1.8,3.0\right.$, and $5.0 \times 10^{-9}$ $\mathrm{cm}^{-2}$ ) in the vertical column of the atmosphere with a crosssection equal to $1 \mathrm{~cm}^{2}$.

contribute in the Mexico City atmosphere. The process of coagulation leads to a decrease in particle concentration, a slight improvement in atmospheric transparency and a decrease in the slope of the $\tau$ versus $\lambda$ dependence. On the other hand, an increase in particle concentration leads to a deterioration of atmospheric transparency and an increase in the slope of the $\tau$ versus $\lambda$ dependence, due to multiple scattering.

Figure 6 shows the results of the measurements of SOD divided into each of four groups of days mentioned above. As a point of reference, the bottom curve in Figure 6a represents the Rayleigh scattering contribution for the Mexico City atmosphere; note that the effects of pollution upon optical thickness far outweigh those from Rayleigh scattering for all observations and at all wavelengths. In Figures $6 \mathrm{a}$ and $6 \mathrm{~b}$, note that the optical thickness is approximately equal at the larger wavelengths but varies substantially at the shorter wavelengths. According to Angström's law this means that stronger episodes of pollution are characterized by steeper slopes of the aerosol particle size distribution. As noted above, in Figure 6a, either there were larger concentrations of relatively small particles in the atmosphere than in Figure 6b or the slope of the dependence $\tau$ versus $\lambda$ changed due to the increased role of multiple scattering; or probably, both effects were present. The conclusion is that strong pollution is characterized by increasing concentrations of small particles and by the increasing role of multiple scattering. As pollution weakens (e.g., Figure 6c), the hypothesis is that the concentration of smaller-size particles decreases with respect to the larger-sized particle. In this case, the spectral dependence of SOD flattens out, being influenced by the giant particles. When cirrus clouds are present, the spectral dependence of SOD becomes almost neutral.

Figure 7 shows averaged curves for the groups shown in Figures $6 \mathrm{a}-6 \mathrm{c}$ and an average curve for all the cloudless days. Figure $7 \mathrm{a}$ shows that the air pollution decreases from case a to case c; however, the Angstrom turbidity coefficient b as defined in equation (4) increases from case a to case $c$. This confusing behavior is due to the fact the Angstrorm turbidity coefficient is defined as the optical depth at the wavelength of $1 \mathrm{~mm}(\mathrm{~b}=\mathrm{t}(1 \mathrm{~mm})$, while the SOD curves shown in Figure 7a cross at a wavelength of about $0.7 \mathrm{~mm}$. It is noted that atmos- pheric turbidity is more accurately defined by the optical depths at shorter wavelengths. In this investigation we choose

$$
\widetilde{\beta}=0.5 \tau \text { (evaluated at } \tau=0.5 \mu \mathrm{m} \text { ) }
$$

which is evaluated outside of the Chappius and other absorption bands. The empirical value of 0.5 in equation (13) is chosen to make $\beta$ approximately equal to Angstróm's turbidity coefficient. As shown in Table 4, the approximation given in equation (13) more faithfully represents the changes of air pollution observed in the Mexico City atmosphere.

Aerosol SOD is approximated using equation (7) for the spectral intervals free of absorption by gaseous components. The parameters of the approximation are given in Table 3 in columns 5 to 8. An examination of Table 3 demonstrates that equation (7) far more accurately represents the Mexico City observations than the Angstrom turbidity given by equation (4).

To isolate the influence of cirrus clouds, the value of SOD averaged from all cloudless days was subtracted from the values measured on April 25, 1992. The result, shown in Figure 8 , is a nearly neutral spectral dependence, which is expected for large ice crystals (or water droplets). The absolute values of SOD for cirrus clouds measured on different davs ranged approximately between 0.3 and 1.6 .

\subsection{Temporal and Spatial Variations}

Temporal variations of reduced SOD are shown in Figure 9 for the complete period of observations at three wavelengths: $350 \mathrm{~nm}, 500 \mathrm{~nm}$, and $850 \mathrm{~nm}$. Variations of atmospheric transparency due to aerosol attenuation are very small during the period of observations: The curves shown in Figure 9 are relatively constant during this 2 -month period. This demonstrates the fact that the atmosphere remains strongly polluted for extended periods of time, with no relief. Only on the evening of June 14, when strong winds blew some of the aerosols out of the atmosphere, did the optical thicknesses decrease significantly. A comparison of SOD values measured in the morning and evening on June 14 is shown in Figure 10. 


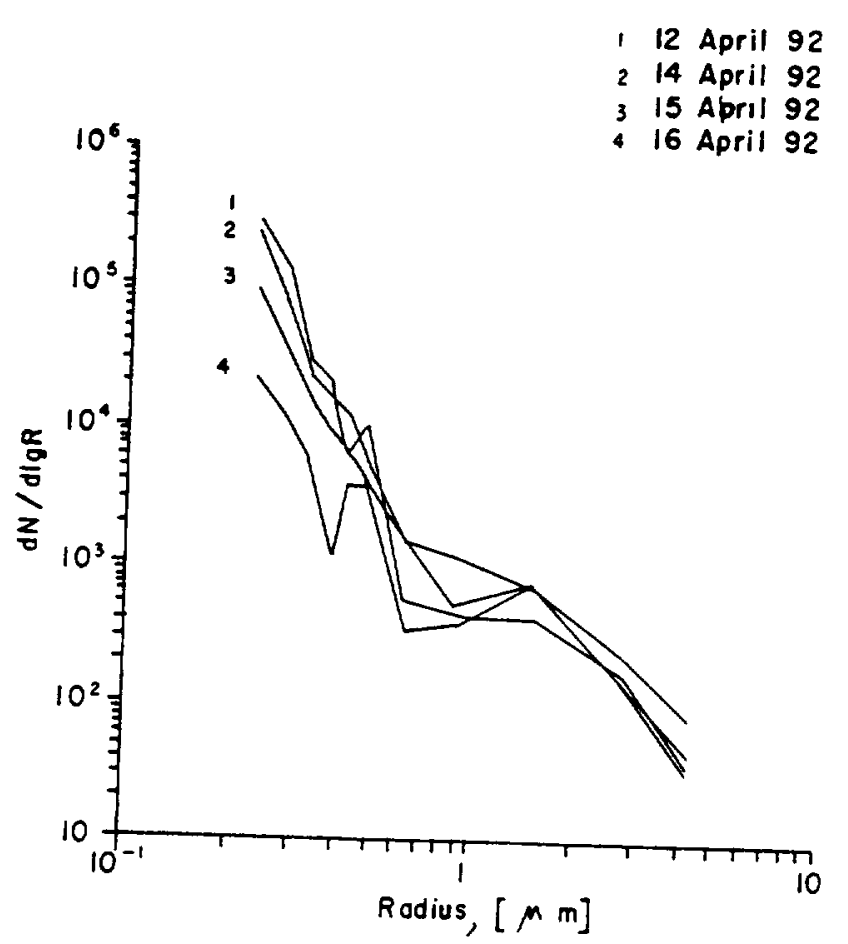

$b$

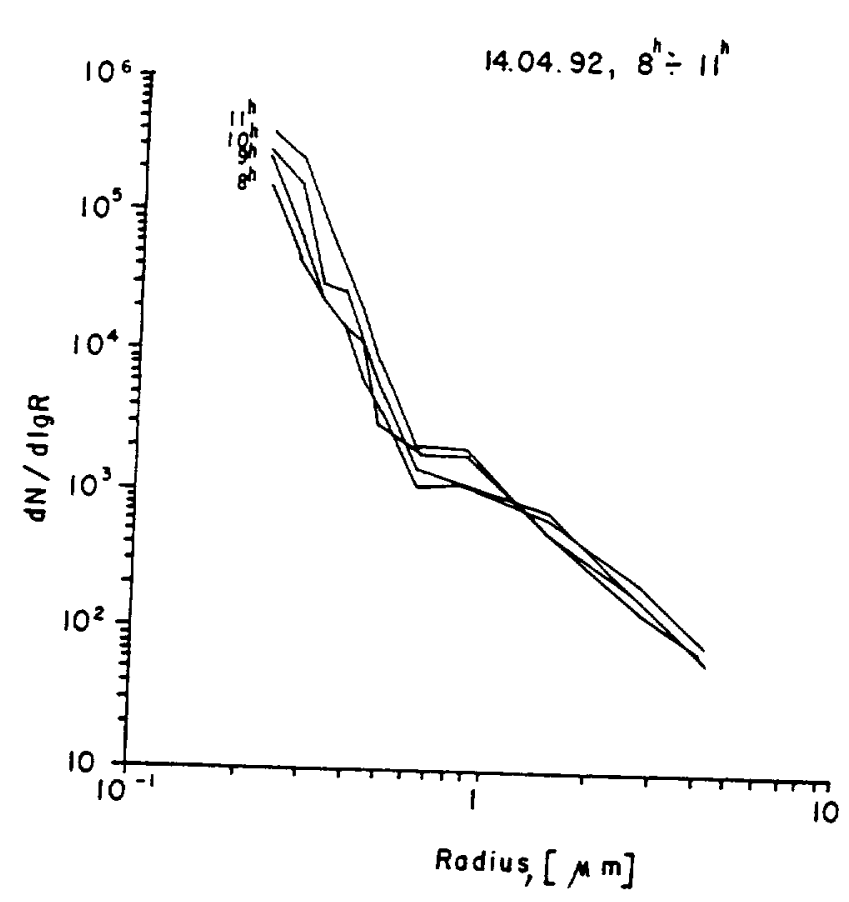

Figure 13. Examples of aerosol size distributions measured near the ground in Mexico City in April 1992 (a) measurements on April 15,14,12, and 16 (from the top to the bottom) at 0800; (b) measurements on April 14 at 1100, 1000,0900 and 0800 (from the top to the bottom).

Optical thickness decreased by about a factor of $3-4$ during this 1-day period.

A comparison of the SOD measured at the site of the University campus with that measured in the center of the city is shown in Figure 11. In the center of Mexico City the SOD values were found to be about $50 \%$ higher in the UV than at the University and about $20 \%$ higher in the NIR.

\subsection{Aerosol Concentration and Aerosol Absorption}

The high values of SOD measured in Mexico City indicate that the concentration of aerosol particles in the atmospheric vertical column exceeds background levels typically found in other regions of the globe by an order of magnitude. Figure 12 shows a set of theoretical calculations made assuming the normalized size distribution of continental aerosols suggested by Valley [1980], and using the optical parameters of dry atmospheric aerosols in accordance with Zuev et al. [1973]. Intercomparison of the theoretical and observed curves suggests that the aerosol vertical column amount is approximately $3 \times 10^{9} \mathrm{~cm}^{-2}$.

Assuming that the aerosol size distribution may be represented by the Junge form as expressed in equation (5), the series of observations taken in Mexico City gave values of 3.25 $<v<3.85$. However, these values of $v$ must be considered only representative for a smoothed distribution of aerosol particles in the whole atmospheric column, because the groundbased measurements showed strong multimodal distributions.

Figure 13 shows examples of aerosol size distributions measured near the ground in April 1992 using the photoelectrical counter AZ-5. As a rule, the aerosol size distributions in Mexico City are multimodal. Aerosol concentrations are measured in the range between $2 \times 10^{4}$ and $3 \times 10^{5} \mathrm{~cm}^{-3}$, the amount of optically active particles being approximately 3 $5 \times 10^{4} \mathrm{~cm}^{-3}$. This means that if the total vertical column concentration of aerosol particles is equal to $3 \times 10^{9} \mathrm{~cm}^{-2}$ (as estimated above), then the height of a homogeneous aerosol layer must be about $0.6-1 \mathrm{~km}$. Similar values are reported by Muhlia et al. [1989].

If we assume that the part of the SOD represented by $\mathrm{C}$ is caused mainly by absorption, then a lower bound on singlescattering albedo $\Phi_{0}$ may be estimated. Figure 14 shows these values of $\omega_{0}$ calculated using the average curves for cloudless days of the groups "a" and "c," as well as the average curve for all the cloudless days of observations. Aeroso: single-scatering albedos for the ensembles of aerosol particles observed in Mexico City have values of $0.7-0.9$ in the UV portion of the spectrum, $0.6-0.8$ in the VIS, and about 0.4 0.7 in the NIR. Figure 14 also shows single-scattering albedos measured in the laboratory for room dust, coal slag, and soot [Lifshits et al., 1966]. Note that the laboratory samples generally indicate an increase in single-scattering albedo with increasing wavelength. However, the measurements in the Mexico City atmosphere show the opposite wavelength dependence, because they characterize ensembles of aerosol particles, which scatter the light more in the shortwave range than in the NIR.

Measurements and calculations of the single-scattering albedo of aerosols over the whole spectral range for urban regions are reported in the literature. Hanel et al. [1990] reports values of $\varpi_{0}=0.67-0.76$ for dry aerosols in Frankfurt, Germany, Ohta et al. [1990] calculated values $\varpi_{0}$ 


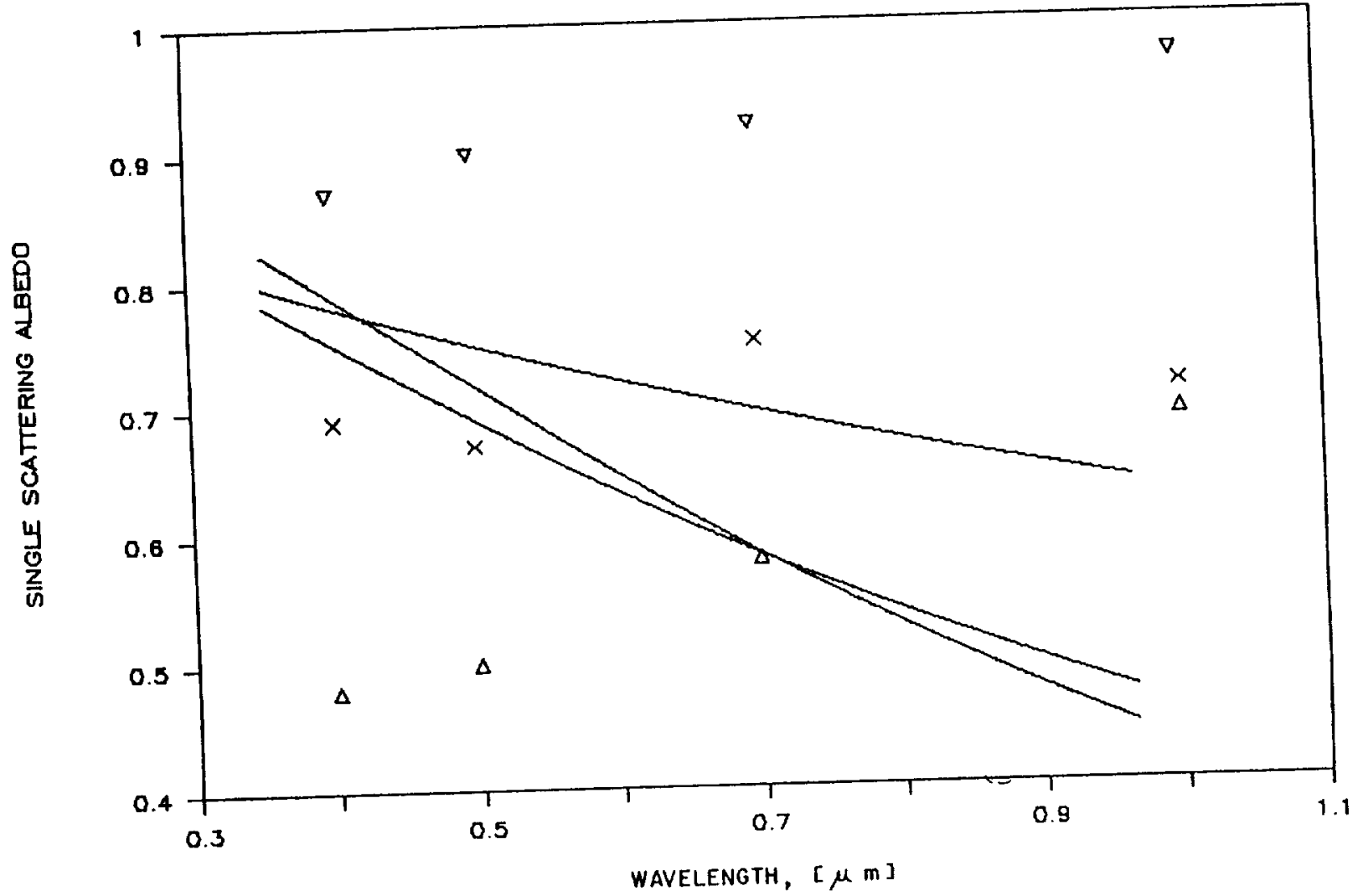

Figure 14. Single-scattering albedo of the ensembles of aerosol particles in Mexico City and analogous values for several organic materials: (1) average curve for the group "a"; (2) average curve for the group "c"; (3) average curve for all groups from "a" to "c"; inverted triangle, room dust; cross, coal slag; traingle, soot.

$=0.8-0.9$ in Sapporo, Japan, on the basis of measured chemical compositions. Mita and Isono [1980] estimated that for $30 \%$ by volume soot content in aerosols the singlescattering albedo may decrease to a value of 0.66 . Also, $\mathrm{Lin}$ et al. [1973] found values of $\bar{w}_{0}=0.68-0.77$ for New York aerosols.

\subsection{Gaseous Absorption}

The average gaseous absorption SOD may be obtained by subtracting the approximated (smoothed) aerosol SOD from the corresponding original curves. Results for the averaged data of the whole period of observations are shown in Figure 15 , which includes the strong absorption bands of (1) ozone $(0.53-0.63 \mu \mathrm{m}) ;(2)$ water vapor $(0.69,0.72,0.82$, and 0.94 $\mu \mathrm{m})$; and (3) oxygen $(0.76 \mu \mathrm{m})$. Also several weak absorption bands are recognized, especially in the UV and VIS. We have not identified all of them, but the maxima on the slope of the ozone absorption band (at wavelengths of $622 \mathrm{~nm}$ and $644 \mathrm{~nm}$ ) probably belong to $\mathrm{NO}_{3}$ [DeMore et al., 1985], which is undoubtedly present in the Mexico City atmosphere. The curve needs more detailed and accurate investigation to identify all of the chemical species. However, this is beyond the scope of the present investigation.

\section{Conclusion}

The observations in the Mexico City atmosphere confirm that the concentration of aerosol particles exceed by an order of magnitude the values found in rural regions. Analysis of measured values of aerosol SOD permit the concentration of aerosol particles to be estimated for the entire vertical column. On some days this value was found to be as large as $3 \times 10^{9} \mathrm{~cm}^{-2}$.

In the UV (at $\lambda \cong 0.35 \mu \mathrm{m}$ ), aerosol optical thicknesses were found to range between 0.6 and 1.2 ; in the visual portion of the spectrum (at $\lambda=0.5 \mu \mathrm{m}$ ) they ranged between 0.5 and 0.8 ; and in the $\mathbb{R}$ (at $\lambda=0.85 \mu \mathrm{m}$ ) the optical thickness ranged between 0.3 and 0.5 . Aerosol particles in the polluted atmosphere of Mexico City were strongly absorbing. Estimates of the single-scattering albedo range between $70-90 \%$ in the UV, $60-80 \%$ in the visual portion, and to $40-70 \%$ in the IR.

The observations show that when the air pollution increases, not only do the values of SOD increase but also the spectral dependence of SOD changes, becoming more characteristic of Mie scattering. The solar radiation scattered by aerosol particles in this polluted atmosphere is of the same order as the radiation scattered by air molecules. In situations of strong pollution the absorption by aerosols in this atmosphere can reach the order of the molecular absorption by atmospheric gases. Hence the SOD of molecular (Rayleigh) scattering, the SOD of molecular absorption, the SOD of aerosol scattering, and the SOD of aerosol absorption of light in the strongly polluted terrestrial atmosphere all are of comparable size.

It was found that in the case of strong pollution the Angstrom turbidity formula poorly represents the observational data. Applying the spectral optical depth (SOD) model of $\tau(\lambda$ 


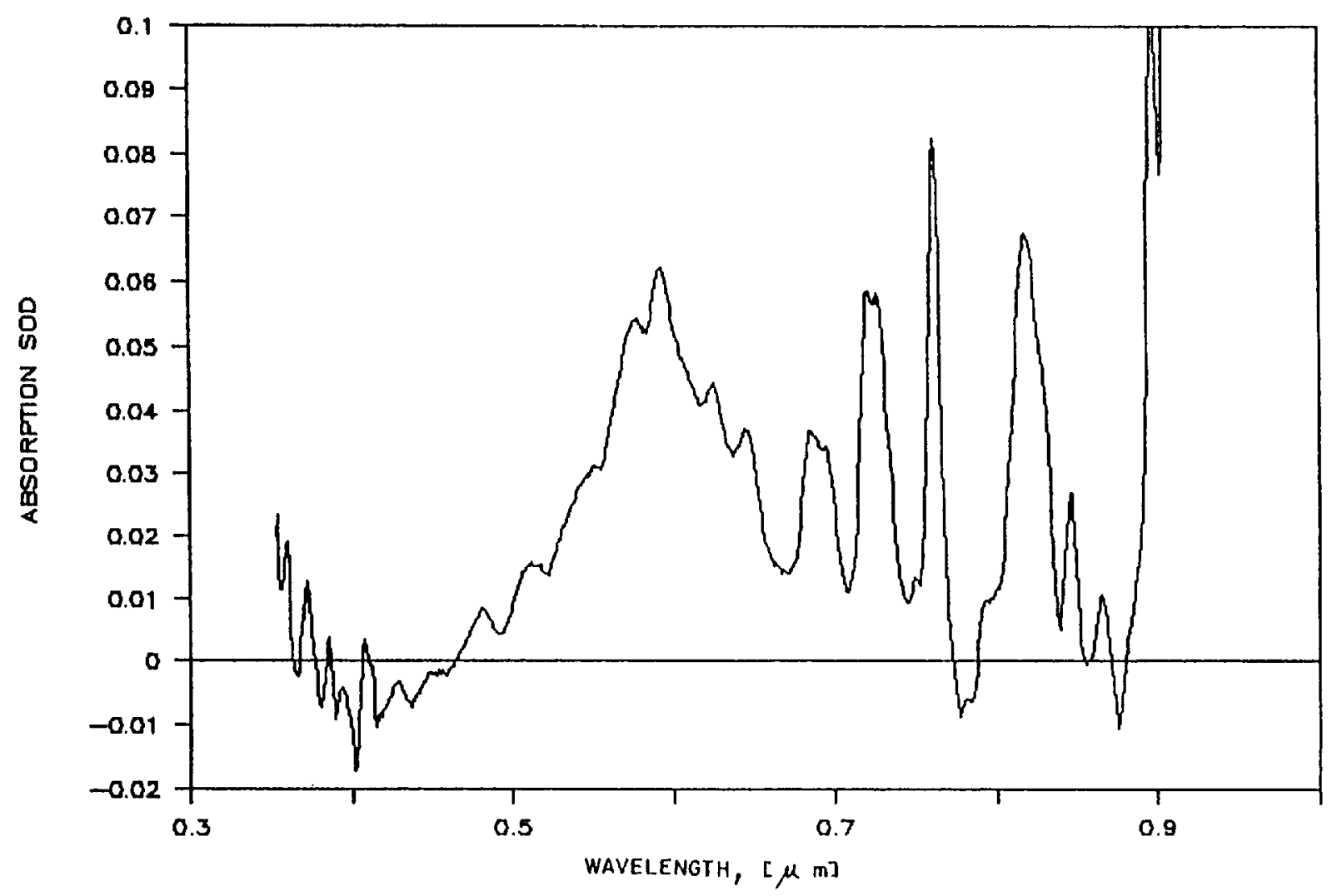

Figure 15. Averaged curve for gaseous absorption SOD in the Mexico City atmosphere, measured during April-June 1992.

) $=\mathrm{C}+\mathrm{A} \lambda^{-\alpha}$, approximate values of $1.55<\alpha<1.85$ were obtained for polluted, cloudless days, with values of $1.25<\alpha$ $<1.60$ on cloudless days with well-recognized haze. Almost neutral dependence of $\tau$ versus $\lambda$ with valulels of $0.65<\alpha<$ 1.05 were obtained on days with cirrus clouds.

The Angstrom turbidity coefficient is widely used in meteorological observations to characterize the degree of air pollution. This approach appears to be adequate in atmospheres with weak and perhaps moderate air pollution. However, in cases of heavy air pollution, as found in Mexico City, it fails to properly represent the actual atmospheric conditions. It is found that one-half the value of optical depth at a wavelength of $1=0.5 \mathrm{~mm}$ is a more faithful characterization of cases with heavy air pollution. According to the Angstrom classification scheme, the Mexico City atmosphere is defined only as "very turbid."

Variations of atmospheric transparency (i.e., aerosol SOD) were very small during the 2 months of observations; that means that the Mexico City atmosphere remains strongly polluted during extended periods of time. Also, air pollution in the center of the city is much higher than at the site of the University campus in the southern region of the city.

Measurements of the aerosol size distributions made near the ground (at shelter height) showed that as a rule they were strongly multimodal. The observed concentrations were in the range between $2 \times \cdot 10^{4}$ and $3 \times 10^{5} \mathrm{~cm}^{-3}$. This means that the height of the homogeneous aerosol layer must be about 0.6-1.0 $\mathrm{km}$.

Calculated spectral dependence of gaseous absorption shows not only well-known strong absorption bands of ozone, water vapor, and oxygen but also several weak absorption bands which were not identified fully. Absorption features at $\lambda=$ $622 \mathrm{~nm}$ and $\lambda=644 \mathrm{~nm}$ probably belong to $\mathrm{NO}_{3}$.

Observations of SOD in Mexico City in 1992 showed without any doubt that atmosphere above the city is tremendously polluted. Only strong winds (e.g., June 14) significantly improved the situation; however, they are seldom found in Mexico City.

Acknowledgments. The authors express their gratitude to the technical personnel of the Laboratory of Experimental Atmospheric Optics IPh SPbSU, the Observatory of Solar Radiation IGf UNAM, and the Aerospace Group II UNAM. The activities were financially supported by the National Council for Science and Technology (CONACyT) of Mexico, from funds of IPh SPbSU, from IGf and II at both UNAM, and from NASA contract NAS 5-31718. They were planned and fulfilled within the framework of the Agreement on Scientific Collaboration between UNAM and SPbSU for 1991-1995. Thanks are extended to anonymous reviewers for their valuable comments.

\section{References}

Ackerman, S. A, and H. Chung Radiative effects of airborne dust on regional energy budgets at the top of the atmosphere, J. Appl. Meteorol., 31, 223-233, 1992.

Albrecht, B. A, Aerosol, cloud microphysics and fractional cloudiness, Science, 245, 1227-1230, 1989.

Angstrom, A, Techniques of determining turbidity of the atmosphere, Tellus, 13, 214, 1961.

Box, G. P., M. A. Box, and A. Deepak: On the spectral sensitivity of the approximate method for retrieving aerosol size distribution from multispectral solar extinction measurements, J. Appl. Meteorol, 20, 944$948,1981$.

Carlson, T. N., Atmospheric turbidity in Saharan dust outbreaks as determined by analyses of satellite brightness data, Mon. Weather Rev., 108, 322-335, 1979. 
Charlson, R. J., J. E. Lovelock, M. O. Andreae, and S. G. Warren, Oceanic phytoplankton, atmospheric sulphur, cloud albedo, and climate, Nature, 326, 655-661, 1987.

Charlson, R. J., S. E. Schwartz, J. M. Hales, R. D. Cess, J. A. Coakley Jr., J. E. Hansen and D. J. Hofmann, Climate forcing by anthropogenic aerosols, Science, 255, 423-430, 1992.

Chung. Y. S., and H. V. Le, Detection of forest fire smoke by satellite imagery, Atmos. Environ., 18, 2143-2151, 1984.

Coakley, J. A. Jr., R. D. Cess, and F. B. Yurevich, The effect of tropospheric aerosol on the Earth's radiation budget: A parameterization for climate models, J. Atmos. Sci., 40,116-138, 1983.

DeMore, W. B., J. J. Margitan, M. J. Molina, R. T. Watson, D. M. Golden, R. F. Hampson, M. J. Kurylo, C. J. Howard, and A. R. Ravishankara, Chemical kinetics and photochemical data for use in stratospheric modeling. JPL Publ., 85-37, Jet Propul. Lab., Pasadena, Calif., 1985.

Elterman, L., Ultraviolet, visible and infrared attenuation for altitudes to 50 km, Environ. Res. Pap. 285, 1968.

Ensor, D. S., L. D. Bevan, and G. R. Markowski, Application of nephelometry to the monitoring of air pollution sources. Proceedings 67th Annual Meeting of the Air Pollution Control Association, APCA Pap. 74-110, Air Pollut. Control Assoc., 1974.

Fraser, R. S., Y. J. Kaufman, and R. L. Mahoney, Satellite measurements of aerosol mass and transport, Almos. Environ., 18, 2577-2584, 1984.

Hanel, G., D. Weidert, and R. Busen, Absorption of solar radiation in an urban atmosphere. Atmos. Environ., 24B(2), 283-292, 1990.

Hansen, J. E., and A A Lacis, Sun and dust versus greenhouse gases: An assessment of their relative roles in global climate change. $\mathrm{Na}$ ture, 346, 713-719, 1990

Iqbal, M., An Introduction to Solar Radiation, 390 pp., Academic, San Diego, Calif., 1983

King, M. D., Sensitivity of constrained linear inversions to the selection of the Lagrange multiplier. J. Atmos. Sci., 39, 1356-1369, 1982.

King M. D., D. M. Bryne, B. M. Herman, and J. A. Reagan, Aerosol size distributions obtained by inversion of spectral optical depth measurements, J. Atmos. Sci., 35, 2153-2167, 1978.

Kondratyev, K. Y. (Ed.): Radiative Characteristics of the Atmosphere and the Earth Surface (in Russian), 564 pp Gidrometeoizdat, St. Petersburg, Russia, 1969.

Kondratyev, K. Y., and O. B. Vasilyev, Die Bedeutung des Aerosols fur den Strahlungshaushalt und sein möglicher Einfluss auf das Klima, Z. Meteorol., 25(3), 129-142, 1975.

Kondratyev, K. Y., S. D. Andreev, I. Y. Badinov, V. S. Srishechkin, and L. V. Popova, Atmospheric optics investigations on Mt. Ellerus, Appl. Opt., 4, 1069-1076, 1965.

Kondratyev, K. Y., O. B. Vasilyev, L. S. Ivlev, G. A. Nikolsky, and O. I. Smiktiy, Infuence of Aerosol on Radiative Transfer: Possible Climatic Consequences (in Russian), 266 pp, LUG, St. Petersburg. Russia, 1973.

Kondratyev, K. Y., O. B. Vasilyev, V. S. Grishechkin, and L. S. Ivlev, Spectral radiative flux divergence and its variability in the troposphere in the 0.4-2.4 $\mu$ region, Appl. Opt., I3 (3), 478-486, $1974 \mathrm{a}$.

Kondratyev, K. Y., O. B. Vasilyev, V. S. Grishechkin, L. S. Ivlev, M. A Prokofyev, and L. I. Chapursky, Spectral shortwave radiative heat fluxes in the troposphere and their possible variations, Izv. Acad. Sci. USSR Atmos. Oceanic Phys., Engl. Transl., 10(5), 298-303, 1974 b.

Kondratyev, K. Y., A A Buznikov, O. B. Vasilyev, and O. I. Smiktiy, Influence of the atmosphere on the albedo in aerospace photography of the Earth in visible light, Izv. Acad. Sci. USSR Atmos. Oceanic Phys., Engl. Transl., 13 (5), 330-340, 1977.

Kondratyev, K. Y., R. M. Welch, S. K. Cox, V. S. Grishechkin, V. A Ivanov, M. A Prokofyev, V. F. Zhvalev, and O. B. Vasilyev,: Determination of vertical profiles of aerosol size spectra from aircraft radiative measurements, 1 and $2, J$. Geophys. Res., 86, 9783-9800, 1981.

Lifshits, G. S., V. E. Pavlov, and S. N. Milyutin, On light absorption by atmospheric aerosols (in Russian), Proc. Astrophys. Inst. A. Kazakh SSR, 7, pp, 1966.

Lin. C.-I., M. Baker, and R. J. Charlson, Absorption coefficient of atmospheric aerosol: A method for measurement, Appl. Opt., 12(6), 1356 $1363,1973$.
Liou, K-N,: An Introduction to Atmospheric Radiation, Int. Geophys. Ser., vol. 26, 392 pp, Academic, San Diego, Calif., 1980.

Mita, A, and K. Isono, Effective complex refractive index of atmospheric aerosols containing absorbing substances, J. Meteorol. Soc. Jpn., 58 (1). 69-79, 1980.

Mitchell, J. M., Jr., Five themes on our changing climate, in Climate in Human Perspectives, A tribute to Helmuth E. Landsberg. pp. 37-59, Kluwer Acad., Norwell, Mass., 1991.

Muhlia, A, A Leyvs, and J-L. Bravo,: Actinometric method for the determination of the total number of aerosol particles in the vertical atmospheric column, Geof. Int., 28 (1), 47-71, 1989.

Ohta, S., N. Murao, and T. Moriya, Evaluation of absorption properties of atmospheric aerosols at solar wavelengths based on chemical characterization, Atmos. Environ., 24A(6), 1409-1416, 1990.

Rasool, S. I. (Ed.), Chemistry of the Lower Atmosphere, Plenum, New York, 1973.

Schneider, S. H., The Genesis Strategy: Climase and Global Survival, Plenum, New York, 1976.

Schwartz, S. E., Are global cloud albedo and climate controlled by marine phytoplankton?, Nature, 336, 441-445, 1988.

Shaw, G. E., J. A. Reagan, and B. M. Herman, Investigations of atmospheric extinction using direct solar radiation measurements made with a multiple wavelength radiometer. J. Appl. Meteorol., J2, 374-380, 1973.

Shifrin, K. S., and I. N. Minin; The theory of non-horizontal visibility. Proc. Main Geophysical Observatory, 68, 1957.

Twohy, C. H., A. D. Clarke, S. G. Warren, L. F. Radke, and R. J. Charlson, Light-absorbing material extracted from cloud droplets and its effect on cloud albedo. J. Geophys. Res., 94, 8623-8631, 1989.

Valley, L. J. (Ed.), Handbook of Geophysics. Macmillan, New York, 1980.

Vasilyev, O. B., On the absorptivity of tropospheric aerosols in the shortwave range, in IRS'92: Current Problems in Atmospheric Radiation, Proc. Int. Radiat. Symp., Tallin, pp 349-352, A. Deepak, Hampton, VA, 1993.

Vasilyev, O. B., V. S. Grishechkin, A. P. Kovalenko, I. A. Tovstenko, E. $O$. Shults, and K. Y. Kondratyev,: Spectral information measuring system for the investigations of the shortwave radiation field in the atmosphere from the Earth's surface and aircrafts, in Complex Remote Monitoring of Lakes, (in Russian), pp. 225-238, edited by K. Y., Kondratyev, Nauka, St. Petersburg, Russia, 1987

Vasilyev, O. B., L. S. Ivlev, A Muhlia Velazquez, A. Leyva Contreras, and $R$. Peralta y Fabi,: Influence of aerosol on radiative transfer in the polluted atmosphere, in IRS'92: Current Problems in Atmospheric Radiation, Proc. Int. Radiat. Symp. Tallin, pp. 195-198, A Deepak, Hampton, VA, 1993.

Welch, R. M., S. K. Cox, and K. Kondratyev, Determination of vertical profiles of aerosol size spectra from aircraft flux measure-ments, II, The effect of particle nonsphericity, J. Geophys. Res., 86, 9795-9800, 1981.

World Meteorological Organization (WMO), A preliminary cloudless standard atmosphere for radiative computation, WCRP, IAMAP Radiation Commission, WCP-112, WMO Tech. Data, 24, Geneva, 1986:

Zuev, V. Y., L. S. Ivlev, and K. Y. Kondratyev, Recent results from studies of atmospheric aerosols, Izv. Acad. Nauk., Atmos. Oceanic Phys., 9(4), 204-371, 1973.

A. Contreras, A. Muhlia Velazquez, R. Peralta y Fabi, and O.B. Vasilyev, Instituto de Geofiscica y Instituto de Ingenieris, UNAM Cd. Universitaria, 04510 Mexico, D.F., Mexico.

L.S. Ivlev, V.M. Jukov, A.P. Kovalenko, and A.V. Vasilyev, Institute of Physics, Saint Petersburg State University, Saint Petersburg, Petrodvorets, 198904, Russia.

R. M. Welch (corresponding author), Institute of Atmospheric Sciences, South Dakota School of Mines and Technology, 501 E. St. Joseph Street, Rapid City, SD 57701.

(Received July 20, 1994; revised June 27, 1995; accepted June 27, 1995.) 